\title{
Design Strategies and Applications of Circulating Cell-Mediated Drug Delivery Systems
}

\author{
Yixue Su, ${ }^{\ddagger}$ Zhiwei Xie, ${ }^{\ddagger}$ Gloria B. Kim, Cheng Dong,* and Jian Yang* \\ Department of Biomedical Engineering, Materials Research Institute, the Huck Institutes of the Life Sciences, The Pennsylvania State \\ University, 205 Hallowell Building, University Park, Pennsylvania 16802, United States
}

ABSTRACT: Drug delivery systems, particularly nanomaterialbased drug delivery systems, possess a tremendous amount of potential to improve the diagnostic and therapeutic effects of drugs. Controlled drug delivery targeted to a specific disease is designed to significantly improve the pharmaceutical effects of drugs and reduce their side effects. Unfortunately, only a few targeted drug delivery systems can achieve high targeting efficiency after intravenous injection, even with the development of numerous surface markers and targeting modalities. Thus, alternative drug and nanomedicine targeting approaches are desired. Circulating cells, such as erythrocytes, leukocytes, and stem cells, present innate disease sensing and homing properties. Hence, using living cells as drug delivery carriers has gained increasing interest in recent years. This review highlights the recent advances in the design of cell-mediated drug delivery systems and targeting mechanisms. The approaches of drug encapsulation/ conjugation to cell carriers, cell-mediated targeting mechanisms, and the methods of controlled drug release are elaborated here. Cell-based "live" targeting and delivery could be used to facilitate a more specific, robust, and smart payload distribution for the next-generation drug delivery systems.

KEYWORDS: drug delivery, nanoparticles, immune cells, circulating cells, stem cells, targeting

\section{INTRODUCTION}

Drug delivery systems (DDS) have been extensively studied during the past several decades as a powerful tool to achieve improved therapeutic efficacy and diagnostic effects by remarkably improving the pharmacokinetics and pharmacodynamics. Recently, a great deal of effort has been made to design novel nanoscale DDS with controlled therapeutic outcomes, targeted modalities toward specific diseases, and minimized side effects. However, traditional DDS, including injection formulations, particles, liposomes, and hydrogels, cannot meet the ever-growing requirements of modern medicine, such as truly targeted therapies and personalized medicine. Thus, cellmediated drug delivery has emerged as a new frontier in medicine. In this review, we will analyze the current design strategies of circulating cell-based drug delivery systems in terms of (1) selecting cells, (2) loading therapeutics into live cells or conjugating therapeutics to the surface of live cells, (3) allowing cell-mediated DDS to target specific diseases, and (4) achieving controlled drug release. The purpose of this review is to summarize the existing designs in constructing circulating cell-mediated DDS and to provide our perspectives on future directions of "live" drug delivery.

Conventional DDS and Their Challenges. Current DDS typically employ vehicles to carry therapeutics in order to improve the drug solubility, reduce toxicity, prolong circulating time, limit biodistribution, achieve specific targeting, control drug release, and diminish immunogenicity. Ideal drug delivery vehicles should be biocompatible, biodegradable, easy to modify, and targeted toward specific diseases. A wide range of vehicles have been employed as controlled DDS, e.g., liposomes, ${ }^{1}$ nanoparticles (NPs), ${ }^{2}$ micelles, ${ }^{3}$ hydrogels, ${ }^{4,5}$ fibers, ${ }^{6,7}$ and films. ${ }^{8}$ Particularly, nano- and micromaterials decorated with targeting ligands or molecules, such as peptides, antibodies, aptamers, and proteins, that are specific to the receptors expressed or overexpressed on aberrant cells and their surrounding microenvironments have been widely studied in targeted drug delivery. ${ }^{9,10}$ Unfortunately, very few of these nanomedicines have shown clinical efficacy due to significant challenges associated with the trafficking and targeting in vivo.

Current targeting strategies can be categorized into passive and active targeting. Passive targeting is typically dependent on enhanced permeability and the retention (EPR) effect caused by leaky vasculature and poor lymphatic drainage. The EPR effect is a unique phenomenon, by which macromolecules and nanoparticles escape from the blood flow and preferentially accumulate more in tumors rather than in normal tissues. It occurs frequently in solid tumors, in which blood vessels commonly have defects. Additionally, defective lymphatic drainage leads to the loss of the ability to clear infiltrating substances. These distinguishing anatomical and pathophysiological characteristics of solid tumors have been generally utilized in tumor targeting. However, passive targeting is largely

Received: December 23, 2014

Accepted: March 12, 2015

Published: March 12, 2015 
chance-dependent. Therefore, active targeting, especially molecular targeting, has been the focus of drug delivery research in recent years. Until now, numerous surface markers have been found on abnormal cells or in their surrounding microenvironment. Integrins, folate, growth factors, and cytokines offer possibility for counter-ligand functionalized drug vehicles to recognize cells and tissue targets. ${ }^{11,12}$ With the capability to bind to specific surface markers, circulating drug carriers may have a higher tendency to attach and accumulate at the sites of diseases such as cancers. In addition, a number of cell-penetrating molecules have also been discovered that can further improve the drug delivery efficiency. ${ }^{13}$ Certainly, the combination of passive and active targeting for drug delivery may yield amplified results.

Despite tremendous efforts made toward discovering novel materials and biomolecule markers for targeted DDS, very few of them are truly specific after intravenous injection and the targeting still remains chance-dependent. Both active and passive targeting approaches require exogenous drug vehicles to disperse and voyage in circulation for a long time to pass through the leaky vasculature or detect the surface markers. However, the circulating environment, in which many drug vehicles cannot have a long enough circulating time to achieve targeted binding, is extremely complicated. ${ }^{14,13}$ In addition, the human body has an innate defense mechanism for invasion. For example, the reticuloendothelial system (RES) rapidly recognizes foreign bodies and destroys them via a series of biological processes. The RES, also called the mononuclear phagocyte system, comprises primarily bone marrow progenitors, blood monocytes, and tissue macrophages. ${ }^{16}$ Furthermore, the EPR effect is somehow heterogeneous in the tumor microenvironments and varies among patients. ${ }^{17}$ For example, hypoxic regions of solid tumor generally do not even exhibit EPR effects because of poor angiogenesis. ${ }^{17,18}$ Considering the complexity and sophistication of in vivo conditions, conventional passive and active targeting strategies still remain inadequate. Hence, developing novel DDS with truly specific targeting is a formidable challenge for modern medicine and nanotechnology.

Cell-Mediated DDS. Recently, cell-mediated DDS have emerged as a promising strategy that is poised to address the above challenges. This novel strategy takes advantage of cell properties, such as long circulation time, abundant surface ligands, flexible morphology, cellular signaling, and metabolism, to offer a unique opportunity to maximize therapeutic outcomes as well as minimizing side effects. The increasing attention toward this field can be seen from the increasing numbers of publications according to Web of Science (Figure $1)$. Here, we review recent advances in the design of cellmediated targeting and drug delivery systems. It is our hope that this review will synergize the current ongoing efforts and lead to future innovations in live cell-mediated DDS.

\section{CIRCULATING CELLS}

Circulating cells can serve as ideal drug delivery carriers for a number of reasons. They are highly mobile and able to travel through blood flow without immunogenicity. Circulating cells are involved in various disease processes, including infection, inflammation, and cancers development, so they can offer multiple advantages for disease targeting. For instance, leukocytes have the innate ability to cross the blood brain barrier (BBB) to access tumor cells in the brain. ${ }^{19}$ Inflammatory responses and wound healing of many diseases involve cell

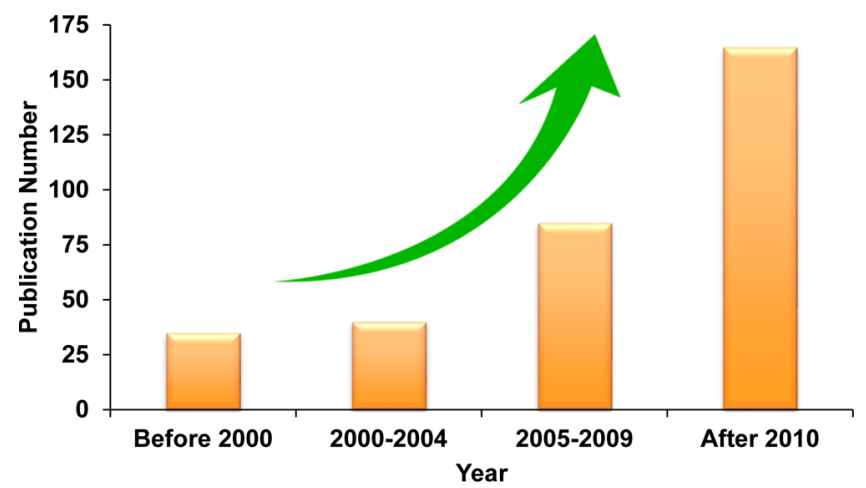

Figure 1. Numbers of publications searched with the keywords of "cell mediated" and "drug delivery". Source: Web of Science.

homing processes that spontaneously attract circulating cells to disease sites. Furthermore, using circulating cells as delivery vehicles is advantageous as it significantly reduces immune clearance and prolongs the biological half-time for drug delivery. Candidate cells to mediate drug delivery include erythrocytes, leukocytes, platelets, and stem cells, whose properties are summarized in Table 1 .

Table 1. Properties of Erythrocytes, Leukocytes, and Stem Cells

\begin{tabular}{|c|c|c|c|}
\hline & erythrocytes & leukocytes & stem cells \\
\hline $\begin{array}{l}\text { amount } \\
((\mathrm{mL} \\
\left.\text { blood })^{-1}\right)\end{array}$ & $4.2-6.0 \times 10^{9}$ & $\begin{array}{l}4 \times 10^{6} \text { to } \\
11 \times 10^{6}\end{array}$ & unknown \\
\hline $\begin{array}{l}\text { diameter } \\
\quad(\mu \mathrm{m})\end{array}$ & $\sim 7$ & $7-15$ & $30-40$ \\
\hline location & blood circulation & $\begin{array}{l}\text { circulation, tissues } \\
\text { and organs }\end{array}$ & $\begin{array}{l}\text { circulation, tissues } \\
\text { and organs }\end{array}$ \\
\hline \multirow[t]{2}{*}{ life span } & $\sim 120$ days & a few days; & $\begin{array}{l}\text { depending on cell } \\
\text { types }\end{array}$ \\
\hline & & $\begin{array}{l}\text { years for memory } \\
\text { lymphocytes }\end{array}$ & \\
\hline functions & transport oxygen & immune defense & $\begin{array}{l}\text { repair tissues and } \\
\text { organs }\end{array}$ \\
\hline \multirow[t]{5}{*}{$\begin{array}{l}\text { pros as } \\
\text { DDS }\end{array}$} & $\begin{array}{l}\text { large } \\
\text { encapsulating } \\
\text { volume; }\end{array}$ & $\begin{array}{l}\text { capable of cross } \\
\text { biological } \\
\text { membrane; }\end{array}$ & potency; \\
\hline & $\begin{array}{l}\text { large surface } \\
\text { areas; }\end{array}$ & tumor-homing; & $\begin{array}{l}\text { homing to injured } \\
\text { cells, tissues and } \\
\text { organs }\end{array}$ \\
\hline & longer life span; & immune response & \\
\hline & $\begin{array}{l}\text { reversible } \\
\text { deformation; }\end{array}$ & & \\
\hline & RES targeting & & \\
\hline \multirow[t]{2}{*}{$\begin{array}{l}\text { cons as } \\
\text { DDS }\end{array}$} & $\begin{array}{l}\text { rapid RES } \\
\text { elimination; }\end{array}$ & short life-span; & $\begin{array}{l}\text { hard to maintain } \\
\text { potency in vitro }\end{array}$ \\
\hline & $\begin{array}{l}\text { drug released off- } \\
\text { site }\end{array}$ & hard to handle & \\
\hline
\end{tabular}

Red Blood Cells. Erythrocytes, or red blood cells (RBCs), make up the largest population of blood cells (>99\%). Approximately 2 million new erythrocytes are continuously produced per second in the human body. RBCs are non-nuclear biconcave discs that average $\sim 7 \mu \mathrm{m}$ in diameter and $\sim 2.5 \mu \mathrm{m}$ in thickness, and have a large internal capacity volume of 185$191 \mu \mathrm{m}^{3}$. Utilizing hemoglobin as an iron-containing protein, RBCs transport oxygen from the respiratory organs to the rest of body. In addition to oxygen, RBCs can carry a range of valuable payloads from therapeutics to imaging contrast agents. 
RBC-based drug delivery has attracted increasing attention for many reasons. RBCs can be easily isolated, frozen, and stored for an extended period of at least ten years. ${ }^{20}$ RBCs in the blood circulation have a life span of 120 days and thus may act as a reservoir for sustained drug release. ${ }^{21}$ The biconcave shape and non-nuclear architecture allow RBCs to encapsulate a large amount of drugs. The membranes of RBCs have reversible deformability, making them capable for taking up payloads via physical methods. Additionally, RBCs are completely biodegradable without producing toxic byproducts, as the RES recognizes old and incompatible RBCs and rapidly removes them. The clearance pathways of RBCs have been widely employed in targeting the RES of the liver, spleen, and bone marrow.

The use of RBCs as drug delivery vehicles, however, still encounters several challenges. RBC carriers can be rapidly eliminated by the RES after drug encapsulation or cellular modification due to potential morphological and functional alterations. The RES rapidly recognizes and eliminates modified RBCs before they reach disease sites, which makes non-RES targeting particularly challenging. Drugs may also be released from destructed cells and result in cytotoxicity. The abundance of RBCs could be a double-edged sword that prevents efficient delivery of therapeutics to disease sites. In addition, RBCs are generally not as selective as other circulating cells in terms of targeting disease sites and promoting the healing process.

Leukocytes. Leukocytes, or white blood cells (WBCs) play significant roles in the immune system, by cleaning cellular debris and defending the body against infections and diseases. Normal human blood contains 4-11 $\times 10^{6}$ leukocytes per $\mathrm{mL}{ }^{22}$ Leukocytes are found in five major types, neutrophils (40-75\%), eosinophils (1-6\%), basophils (less than 1\%), monocytes $(2-10 \%)$, and lymphocytes (20-45\%). Although the lifespan of leukocytes (up to 20 days) is typically shorter than that of RBCs, their specialized functions make them attractive as drug delivery carriers because leukocytes are involved in various immune responses, cellular interactions, cell adhesion, and are capable of penetrating through biological barriers into nonvascular areas. Neutrophils, monocytes/ macrophages, and lymphocytes are all potential candidates for delivering therapeutics to treat various diseases.

Neutrophils, also known as polymorphonuclear granulocytes (PMNs) that contain distinctive cytoplasmic granules, are the most abundant leukocyte found in the human body. They are the first cells that arrive at the sites of infection or inflammation, produce cytokines to recruit other cells, and are cleared after a few days. ${ }^{23}$ Neutrophils also engulf invading microorganisms or foreign substances and consequently eliminate the invaders using digestive enzymes (e.g., lysozyme, hydrolytic enzymes, and myeloperoxidase) or respiratory burst. ${ }^{24}$ Unfortunately, neutrophils have the average lifespan of 5.4 days in circulation and only a few hours after their isolation from blood. ${ }^{25}$ The short life span of neutrophils limits their applications in DDS, but their ability to immediately migrate and transport make them attractive as drug carrier candidates.

Monocytes are mononuclear leukocytes with kidney-shaped nuclei and clear cytoplasm. They are produced from stem cell precursors in the bone marrow. Monocytes circulate in the bloodstream and migrate to tissues, particularly the liver, lymph nodes, and lungs. Meanwhile, monocytes continuously migrate to and accumulate at disease sites in association with infection or inflammation. ${ }^{26,27}$ Once leaving the blood flow, monocytes differentiate into macrophages in response to various stimulations. Otherwise, they return to the bone marrow without activation. Macrophages play versatile roles in inflammation, cell recruitment, cytokine and growth factor secretion, and bacteria/cellular debris clearance. Emerging studies also indicate that macrophages are the major players in disease microenvironments and disease progression, such as in cancer invasion. ${ }^{28,29}$ Additionally, monocytes/macrophages present phagocytic capability that enables the spontaneous encapsulation of drugs/particles.

Lymphocytes are identified by their large nucleus surrounded by a thin layer of cytoplasm. The average diameter of lymphocytes is $7-15 \mu \mathrm{m}$. Lymphocytes are primarily found in the circulation and central lymphoid organs such as the spleen, tonsils, and lymph nodes. ${ }^{30} \mathrm{~T}$ cells and B cells are the major types of lymphocytes and are responsible for the adaptive immune system. $T$ cells mature in the thymus and play a critical role in cell-mediated immunity and can be broadly divided into helper $\mathrm{T}$ cells, cytotoxic $\mathrm{T}$ cells, and regulatory $\mathrm{T}$ cells. ${ }^{31}$ When an antigen appears, antigen-presenting cells (APCs) recognize and present the antigen to $\mathrm{T}$ cells. Then, helper $\mathrm{T}$ cells secrete various cytokines, which stimulate toxic $\mathrm{T}$ cells to directly kill abnormal cells. Regulatory $\mathrm{T}$ cells are also activated to suppress immune response in order to maintain immunological tolerance. B-cells are produced in the bone marrow and involved in humoral immunity. B cells make antibodies against antigens and can be characterized by the presence of immunoglobulin on their surface. ${ }^{32}$ Meanwhile, B cells can differentiate into memory B cells, which respond rapidly when exposed to the same antigen. Thus, both lymphocytes present multiple functions in human immunity and are involved in numerous diseases: detecting antigens, infiltrating disease sites, and attacking abnormal cells. Clearly, lymphocytes could serve as a potential platform to deliver drugs specifically.

Overall, leukocytes have a rapid response and intrinsic homing properties with respect to infections, inflammations, and tumors. Such sensitive detections and biological barriers infiltration abilities give rise to opportunities for leukocytesmediated drug delivery. However, vulnerable leukocytes are difficult to harvest and handle with relative short life spans, which hinder the manipulation processes for loading drugs and NPs.

Stem Cells. Stem cells are self-renewable with a potential to differentiate into various cell types and therefore essential in tissue repair and regeneration. They are broadly classified into two categories according to their source and plasticity: embryonic stem cells and adult stem cells. Embryonic stem cells originate from the inner cell mass of a blastocyst in an early stage embryo, which are pluripotent that can generate all cell types in the body. Adult stem cells are tissue-specific stem cells that can differentiate into limited specialized cells. ${ }^{33}$ Stem cell therapy has been significantly explored in tissue engineering, regenerative medicine, and even translated into clinical trials. ${ }^{34,35}$ Utilizing stem cells as drug carriers can be particularly beneficial because it may add another dimension into existing stem cell therapy. Current stem cell therapies including those for neurological disease, heart disease, and cancer can all be improved by incorporating therapeutics into stem cells. Interestingly, stem cells are inherently tumor homing, which is mediated by inflammatory factors, tumor-derived factors, and tumor-specific receptors. ${ }^{36,37}$ Generally, stem cells take 2-4 days to migrate to tumor sites. ${ }^{38}$ Thus, stem cells also have natural living targeting capabilities that response to diseases and tissue regeneration. Additionally, stem cells are relatively easy 


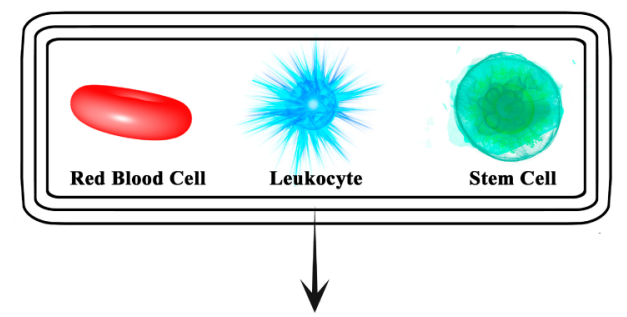

Circulating cell

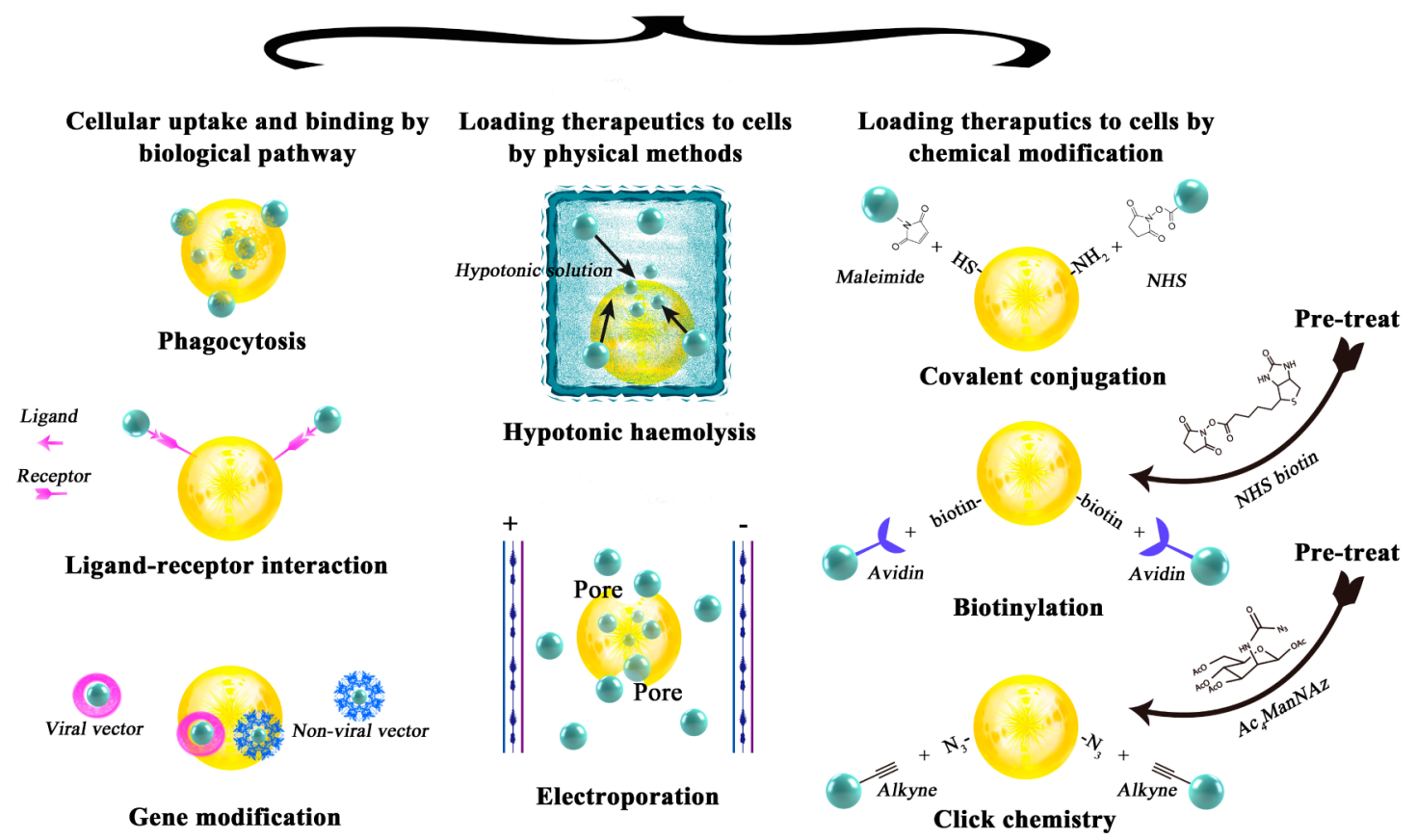

Figure 2. Strategies of encapsulation and conjugation of drugs/particles onto/into circulating cells, including red blood cells (RBCs), leukocytes, and stem cells, by biological, physical, and chemical means.

to harvest and culture in vitro, and can be induced to differentiate into specialized cells under certain conditions. These properties make stem cells promising candidates for targeted drug delivery.

\section{ENCAPSULATION/CONJUGATION OF DRUGS/PARTICLES TO CIRCULATING CELLS}

To obtain cell-mediated drug delivery, drugs or drug-loaded particles should be able to attach onto or internalized into cells to form drug-cell or particle-cell complexes. The basic requirements for drugs and drug-loaded particles in cellmediated delivery are no or low toxicity to cell carriers, particle degradability, and controlled release of drugs. For drug/ particle-cell complexes, strong binding between payloads and cell carriers, long circulating time, and low immunogenicity are desired. The use of cell carriers should not only transport drugs in high specificity to target tissues, but also regulate pharmacokinetics and pharmacodynamics via altering the properties of biomaterials that are used to encapsulate therapeutics. To date, drug vehicles can be added to cells by biological pathways, physical approaches or chemical modifications (Figure 2).

Cellular Uptake and Binding by Biological Pathways. The most straightforward way to load drugs with circulating cells is using unmodified cells, which possesses natural biological pathways that can be utilized. Biological pathways represent a series of actions that regulate cell behavior and fate at the molecular level. Various cells are able to load drugs via different pathways. In these cases, their morphology and functional integrity can be largely preserved. In this section, we will review the pathways that facilitate the encapsulation of drugs or genes within cells and/or conjugating nanoparticles onto the surface of cells. Loading therapeutics via physical and chemical modifications of cells will be reviewed in later two sections, respectively.

Endocytosis. Endocytosis is a fundamental cellular process, by which eukaryotic cells engulf fluid, molecules, and even other cells. ${ }^{39}$ Most substances, especially large and polar molecules, cannot directly pass through the hydrophobic cell membranes. Endocytosis provides a pathway to internalize these substances via plasma membrane deformation. During this process, plasma membranes invaginate and form intracellular vesicles around the substances to be internalized, followed by the membrane fusion. Endocytosis is dominated by several parameters such as sizes, shapes, charges, and mechanical properties of the foreign substances. ${ }^{40}$ It offers an opportunity to regulate the encapsulation of drug vehicles by an endocytosis-dependent pathway.

Pinocytosis is a mode of endocytosis that can nonspecifically "drink" the surrounding liquid and molecules. Eukaryotic cells 

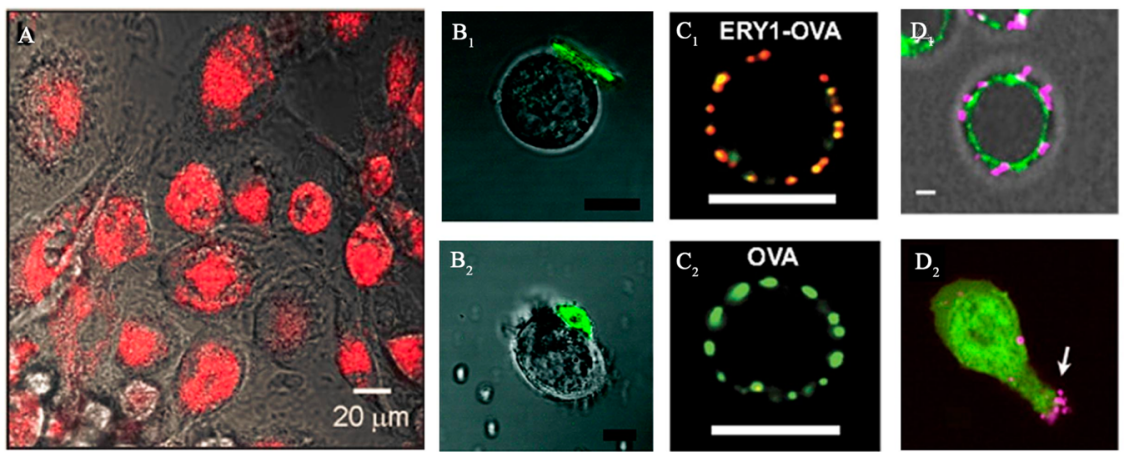

Figure 3. Examples of drugs/NPs internalized into or conjugated onto circulating cells via innate cellular uptake/binding. (A) Endocytosis pathway. Fluorescence microscopy images of phagocytosis of gold silica nanoshells (red) by macrophages. ${ }^{54}$ Reprinted with permission from ref 54 . Copyright 2012, PLOS ONE. (B) Ligand-receptor interaction. Confocal microscopy images of HA functionalized PEM-based cellular patches (green) attached on the surface of a $T$ cell $\left(B_{1}\right)$ and a $B$ cell $\left(B_{2}\right)$ via CD44 reorganization. Scale bar, $10 \mu \mathrm{m} .{ }^{62}$ Reprinted with permission from ref 62 . Copyright 2008 American Chemical Society. (C) Specific ligand-receptor interaction that exclusively occurs in certain cells. Confocal microscopy images of OVA (red) conjugated ERY1 peptide, binding to a mouse RBC (labeled with antimouse glycophorin-A, green) through glycophorin-A, $\mathrm{C}_{1}$; instead, no free-OVA observed on RBC, $C_{2}$. Scale bar, $5 \mu \mathrm{m} .{ }^{70}$ Reprinted with permission from ref 70 . Copyright 2013 National Academy of Sciences. (D) Covalent conjugation. Confocal microscopy images of D1: Maleimide-functionalized liposome-coated NPs (purple) conjugated on T cells (green) via thiol groups; D2: NPs relocated during migration. Scale bar, $2 \mu \mathrm{m} .{ }^{71}$ Reprinted with permission from ref 71 . Copyright 2012 Elsevier.

continuously conduct pinocytosis and are prone to engulf relatively small molecules. This plasma membrane homeostasis process has been utilized to encapsulate bare drugs into erythrocytes in early attempts. Drugs, such as hydrocortisone, primaquine, vinblastine, and chlorpromazine, can directly induce erythrocyte membrane internalization by pinocytosis. ${ }^{41-43}$ The formation of vacuoles is age-related. ${ }^{44}$ Pinocytosis is adenosine triphosphate (ATP)-dependent and influenced by the drug concentration, temperature, $\mathrm{pH}$, and the balance between the concentrations of magnesium and calcium in the cell membrane. ${ }^{45,46}$ These drug-loading methods are based on simple absorption; however, they tend to induce potential cytotoxicity.

In contrast to pinocytosis, phagocytosis sporadically occurs in specialized cells (e.g., neutrophils, macrophages, lymphocytes, and dendritic cells). Stimulated by immune responses, these white blood cells can internalize particles in nano or micro sizes via an actin-dependent mechanism associated with receptor reorganizations such as Fc receptors, complements, and mannoses. ${ }^{47}$ The sizes of drug vehicles, including NPs, micelles, and liposomes, commonly fall in this range. Then, the engulfed particles fuse with lysosomes that are later broken down by abundant digestive enzymes in lysosomes. Because phagocytosis is a type of immune defense procedures against foreign invaders, including drugs or drug-encapsulated particles, it gains tremendous interest in cell-mediated DDS design. Drug-laden particles are susceptible to rapid RES clearance in vivo, which means immune cells are the first cells to sense and catch particles during circulation. Instead of designing particles to overcome rapid RES elimination, phagocytic cells can be rationally utilized as delivery carriers. Further, phagocytosis can be significantly enhanced by opsonization, by which particles are coated with proteins and/or antibodies to enable the rapid reorganization of particles by the mononuclear phagocytic system. $^{48}$ For example, immunoglobulin and albumin were coated on superparamagnetic iron oxide nanoparticles (SPIO NPs) to facilitate the monocyte-macrophage uptake. ${ }^{49}$ Compared with pristine SPIO NPs, a larger amount of opsonized-SPIO NPs accumulated in the monocyte nuclear periphery. ${ }^{49}$
Numerous nanomaterials, including inorganic NPs, polymeric NPs, and liposomes, have been successfully loaded into phagocytic cells and delivered to target various diseases (Figure $3 \mathrm{~A}) .{ }^{50-54}$ One important understanding in the application of phagocytic cell carriers is that the material geometry plays a significant role in regulating cell internalization. Specifically, particle size is crucial in this process, since phagocytosis takes place at the nano/microscale level. ${ }^{55,56}$ IgG-opsonized and nonopsonized polystyrene (PS) microspheres with an average diameter of $2-3 \mu \mathrm{m}$ exhibited the highest internalization in a rat alveolar macrophages phagocytosis model. ${ }^{55,56}$ Material geometry also affects phagocytosis. Champion et al. studied phagocytosis of alveolar macrophages and cultured the cells with PS particles with various sizes and shapes. ${ }^{57}$ Results suggested that macrophage internalization largely depends on the local particle shape at point of initial contact. The local particle shape is defined as the angel $(\Omega)$ between the normal of initial cell/particle contact point and a vector from the initial contact point to the center point of the particle contour. Thus, $\Omega$ represents the local curvature. There is a critical point, $\Omega=$ $45^{\circ}$, where the internalization cannot be observed. Phagocytosis does not occur any more where is $\Omega>45^{\circ} .{ }^{57}$ The relationship between local particle shape and phagocytosis leads to so-called shape engineering, which is important in cell-mediated drug delivery. Additionally, macrophage phagocytosis is regulated by the mechanical properties of the substrates, as macrophages show a strong preference to engulf rigid objects. ${ }^{58}$ For example, macrophages internalized about 6 times IgG opsonized polyacrylamide microbeads with a higher cross-linking rate (stiff beads) than those soft beads with 4 times lower crosslinking rate. ${ }^{58}$ The effect of surface charge on phagocytosis, however, raises a controversy. Ari et al. coated drugs with poloxamer and/or phospholipid surfactants to form NPs with various surface charges. They found that positively charged NPs accumulate more in macrophages than negatively charged NPs. ${ }^{51}$ But liposomes with negative charges on surfaces were uptaken more by macrophages through the scavenger receptor recognition. ${ }^{59,60}$ These paradoxical observations might be due to various phagocytic pathways adopted in the cellular uptake of different materials. 
Certainly, it is also important to prevent drug release within phagocytic cells before reaching the target disease site, because it may compromise the therapeutic effects and also damage cell carriers. In some cases, it is necessary to inhibit phagocytosis, because cells may rapidly degrade the internalized particles. Thus, the design of drug-loaded particles is critical to achieving ideal particle location. Generally, it is considered that surface anchored particles would be ideal. For example, wormlike particles with very high aspect ratios $(>20)$ was designed to partially inhibit macrophage phagocytosis in order to protect the drug during the circulating and targeting processes. ${ }^{61}$

Therefore, endocytosis is a powerful and tricky pathway to load drugs and/or NPs. However, due to its complexity involving diverse receptors and a series of fusion and fission events, precisely controlling cell internalization is still a significant challenge. New techniques to fine-tune particle properties and endocytosis processes are still needed to improve endocytic cell-mediated nanoparticle delivery.

Ligand-Receptor Interactions. Ligand-receptor interactions are one of the most basic ways for cells to communicate with each other and the environment. Cellular receptors are generally embedded within plasma membrane surfaces, which contain specific sites for ligand binding and vice versa. Ligandreceptor interactions have been utilized by currently active nanoparticle targeting strategies due to its selectivity and specificity. Thus, this approach also can be used to load particles onto/into circulating cells. Considering that circulating cells are relatively rich in receptors on the surface, a variety of drug carriers have been linked to them via ligand-receptor interactions.

As an example, CD44 markers are involved in cell adhesion and extensively expressed on a large number of circulating cells, e.g., leukocytes and stem cells. CD44 is also a receptor for hyaluronic acid (HA), which is a glycosaminoglycan that can be found in the extracellular matrix. $\mathrm{HA}$ is a promising drug delivery material that is known for its biocompatibility and intrinsic binding capability to CD44. HA coated polyelectrolyte multilayer (PEM) cell patches were developed to attach on the surfaces of $\mathrm{B}$ and $\mathrm{T}$ lymphocyte by binding to the CD44 on surfaces (Figure 3B). ${ }^{62,63}$ The cell-PEM-HA complexes retained strong retention that can be controlled by varying the size of the patches and the ratio of cells to patches. ${ }^{64}$ The binding efficiency between PEM-HA and B cells increased at lower $\mathrm{pH}$ and higher $\mathrm{NaCl}$ concentrations. ${ }^{63}$ This phenomenon may result from the change of HA conformation that exposed more binding sites to CD44 receptor. ${ }^{63}$ Compared to conventional spherical particles of equal volume, the low curvature particles significantly decreased cell uptake. Interestingly, flat PEM-based disks with $\sim 6 \mu \mathrm{m}$ average diameters that exhibited low phagocytosis were able to tightly attach on cell surfaces. ${ }^{65}$ This so-called cellular backpack is an alternative approach for cell-mediated drug delivery by attaching drugloaded particles on cell surfaces, maximizing protection for therapeutic payloads and cell integrity. The cellular backpack achieved controlled release of drugs since the drugs were encapsulated in biodegradable poly(lactic-co-glycolic acid). ${ }^{65}$ These approaches are promising in preventing drug release offsite, avoiding RES elimination, and enhancing the retention time of NPs in blood flow. Most recently, self-assembled thermosensitive poly(ethylene glycol) methacrylate-HA nanogels were found to be rapidly phagocytized by macrophages and accumulated in the liver and spleen $13 \mathrm{~min}$ after intravenous injection in mice. This study also suggested that HA-CD44 binding was effective for attaching nanocarriers on macrophages. ${ }^{66}$ These macrophage/nanogel complexes have shown potential in drug delivery for macrophage-associated diseases.

The cell-particle encapsulation/conjugation also can be achieved by antibody-antigen interactions. Silica nanorattles, namely hollow silica spheres with moving cores, were bioconjugated with monoclonal antibody to recognize membrane proteins of CD73 and CD90 on mesenchymal stem cells (MSCs). ${ }^{67}$ After antibody-antigen recognition, antibodymodified nanorattles were internalized within MSCs, suggesting that multiple pathways were involved in the process. ${ }^{69}$ Each MSC can retain up to 1500 nanorattles for at least $48 \mathrm{~h}$, which is sufficient for MSCs to migrate to tumor sites. ${ }^{67}$

Additionally, some receptors only exist in particular cell types, granting opportunities for cells taking up particles in the circulation instead of assembling the cell-drug complex in vitro. For instance, complement receptor type 1 (CR1) is primarily expressed on RBCs. Monoclonal antibody (mAb) against CR1 (Anti-CR1) was conjugated on a tissue-type plasminogen (tPA) activator in order to couple with RBC carriers. ${ }^{68}$ Anti-CR1/tPA can rapidly bind to RBCs to prolong circulation time. ${ }^{68}$ Glycophorin A is another erythrocyte specific surface marker. ERY1 is a 12 amino acid peptide that is able to specifically bind to the RBC surface via glycophorin A. ${ }^{69}$ Antigen ovalbumin conjugated with ERY1 spontaneously recognized RBCs within $30 \mathrm{~min}$ and remained tightly bind for at least $72 \mathrm{~h}$ after intravenous injection in mice (Figure $3 \mathrm{C}$ ) ${ }^{70}$ However, to the best of our knowledge, no drug-loaded particle has been conjugated to circulating cells through these specific interactions.

Thus, ligand-receptor binding is a powerful method to attach particles to circulating cells. Advances in cellular engineering with discoveries of new surface markers and binding ligands are beneficial for ligand-based drug carrier design. Improving the binding efficiency on particular cell types is still remaining as a challenge. It is also desired to accomplish in vivo specific binding within the blood circulation.

Gene Modification and Delivery. Great efforts have been made to insert therapeutic plasmid DNA, mRNA, and siRNA into living cells to build novel gene or drug delivery systems. Transduction and transfection, both of which are powerful ways to obtain a large number of functional cells in vitro and in vivo, can introduce foreign genes, including therapeutic genes, into host cells. ${ }^{72,73}$

Cell-mediated viral delivery to tumors has been well studied. Oncolytic virus (OV) is an anticancer agent that can selectively induce cell death in cancer cells, while leaving normal cells healthy. ${ }^{74}$ Transduction can effectively introduce OVs into circulating cells based on a virus-mediated DNA transfer mechanism. Furthermore, OVs can be transported with cell carriers to tumors, followed by local replication and amplification to suppress tumor growth. A variety of OVs, such as adenovirus, herpes simplex virus, poxvirus, vesicular stomatitis virus, measles virus, Newcastle disease virus, influenza virus, and reovirus, has been combined with different cell-based delivery systems. For example, mesenchymal progenitor cells (MPCs) have served as vehicles to deliver oncolytic adenoviruses. ${ }^{75}$ To enhance transduction efficiency, oncolytic adenoviruses were first genetically modified with cellular integrin-binding motifs. ${ }^{76}$ Transfused MPCs maintained their intrinsic capacity of sensing tumors and further improved the therapeutic effects in an ovarian carcinoma model. ${ }^{75}$ Additionally, human activated $\mathrm{T}$ lymphocytes infected with 
oncolytic measles viruses were able to transfer viruses to tumor cells via the heterologous cell fusion, and subsequently deliver viruses to myeloma. ${ }^{7}$

Virus therapy is widely studied, but its clinical safety is still a concern because of rapid proliferation of viruses, off-target cytotoxicity, and body antiviral immunity. Nonviral transfection is an alternative strategy to introduce therapeutic nucleic acids into cellular carriers. $\mathrm{Hu}$ et al. developed nonviral vehicles, based on low-molecular-weight polyethylenimine-co- $\beta$-cyclodextrins $(\beta-\mathrm{CD})$, to transfect tumor necrosis factor (TNF)related apoptosis-inducing ligands (TRAILs) into circulating MSCs. ${ }^{78}$ MSC-TRAILs efficiently killed tumor cells in a lung metastasis model. In order to achieve noninvasive drug delivery and MRI contrast capabilities, light sensitive, gold-coated SPIO core-shell magnetic NPs (SPIO@AuNPs) were transfected into cell adipose-derived MSCs. ${ }^{79}$ Adipose-derived MSCs retained high cell viability, osteogenic differentiation, and disease homing ability after transfection. Interestingly, SPIO@ AuNPs stimulated cell growth at a certain concentration $(<10$ $\mu \mathrm{g} / \mathrm{mL}$ ) and did not induce pro-inflammation, which is typically promoted by other SPIO NPs. ${ }^{80}$

With the help of genetic modifications, cell carriers are capable of constantly expressing desired therapeutic or imaging molecules. Because transduction/transfection permanently alters cell properties, it inevitably gives rise to safety concerns and even ethical issues. Researchers should take them into account when applying genetic modifications.

Loading Therapeutics to Cells by Physical Methods. RBCs possess various reversible transformation capabilities that allow for drug loading simply with external physical treatments such as hypotonic hemolysis and electroporation (Figure 2). These approaches are relatively easier to handle in vitro and eliminates the use of chemical reagents to reduce possible alterations of RBCs. RBCs can recover to their normal morphology and maintain the role of transporting therapeutics and particles to targeted sites.

Hypotonic Hemolysis. Hypotonic hemolysis has been widely applied in RBC encapsulation. RBCs behave like osmometers that shrink in hypertonic conditions and swell in hypotonic conditions. Pores open on cell membranes, when the critical hemolytic volume is reached. The increased cell membrane permeability in hypotonic solution enables the entrapment of drugs, biomacromolecules, and NPs in RBCs by a passive mechanism. ${ }^{81,82}$ The principle of reversible swelling is based on the fact that the absence of a superfluous membrane allows cells to accommodate additional volume by changing the shape from biconcave to spherical. Several hypotonic hemolysis techniques have been generated, such as hypotonic dialysis, hypotonic dilution, and hypotonic preswelling. ${ }^{83,84}$ Hypotonic dialysis is predominantly applied in encapsulating enzymes, proteins, and contrast agents because of its relative ease of use, ability to preserve cell characteristics and high encapsulation rate. In the process, erythrocytes with a hematocrit value of $70-80 \%$ are prepared in a dialysis tube and immersed in a hypotonic buffer for a few hours under gentle stirring. The techniques have been applied in encapsulating drugs, enzymes, and proteins since the 1970s. ${ }^{85-90}$ Peptide nucleic acids (PNAs), as therapeutic agents, were loaded into RBCs via hypotonic dialysis and achieved $82 \%$ encapsulation after $18 \mathrm{~h}$ incubation. ${ }^{88}$ PNAsladen $\mathrm{RBCs}$ underwent opsonization with $\mathrm{ZnCl}_{2}$ and bissulfosuccynimidil-suberate treatment, and then specifically targeted macrophages. PNAs were effectively delivered and resulted in reduced production of nitric oxide and inhibited protein expression of the enzyme nitric oxide synthase. ${ }^{88}$

Electroporation. Electroporation is a physical method that uses an electrical pulse to create temporary pores on cell surfaces. ${ }^{91}$ Cells are typically suspended in a conductive solution and exposed to a high-intensity external electrical field. The disturbance of the phospholipid bilayer induces temporary dysfunctions of the cell membranes, resulting in the encapsulation of exogenous molecules in cells. During the process, cells keep their morphology when engulfed molecules are larger than the size of electropores. However, cells may swell and the cell membranes may rupture if the substances are smaller than the size of electropores. ${ }^{92}$ Various compounds such as drugs, enzymes, and genes have been encapsulated within RBCs accomplished with sustained release. ${ }^{93-95}$ The drawbacks of electroporation are obvious. The electrical force causes irreversible deterioration and the recovery rate is commonly low. ${ }^{95}$ Thus, it is necessary to optimize the applied voltage to keep cell integrity in electroporation.

Loading/Conjugating Therapeutics into/onto Cells by Chemical Modifications. Compared to biological and physical methods to load drugs into cells, chemical modification may fix drugs and drug vehicles onto/into circulating cells and avoid the metabolic degradation of materials and drugs within the carrier cells. The surface of circulating cells is a highly heterogeneous structure composed of different proteins, lipids, and carbohydrates with various functional groups for chemical modification opportunities as mentioned previously. ${ }^{96,97}$ Furthermore, chemical modification is not solely dependent on the naturally available cell surface molecules. The complexity of the cell membrane offers alternatives to introduce additional functional groups for a number of conjugating reactions. Compared to pristine cells, modified cells enable convenient conjugations with therapeutics and particles via versatile chemistry tools (Figure 2).

Covalent Conjugation onto Surface Markers. A number of functional groups have been discovered on different cell surfaces that allow bioconjugation with molecules or particles. Among the available functional groups, primary amine and thiol groups are mostly used for covalent reactions due to the ease of labeling and low toxicity of the reactions. N-Hydroxysuccinimide (NHS) ester-based cross-linkers are most popular for primary amines modification via carbodiimide reaction. Rossi et al. grafted hyperbranched polyglycerol (HPG) onto the surface of RBCs to generate immunocamouflaged cells. ${ }^{98}$ HPG is a hemocompatible polymer with abundant hydroxyl groups that are ideal for surface modification. HPG was functionalized with succinimidyl succinate (SS) groups by initially reacting with succinic anhydride and then with NHS. ${ }^{98}$ SS-HPG was eventually grafted with primary amine groups presented on the RBC surfaces. Also, the thiol groups in cysteine containing membrane proteins are available for coupling via maleimidethiol conjugation. Maleimide-functionalized liposome-coated NPs were conjugated on the surface of lymphocytes and MSCs. ${ }^{99}$ The attachment of NPs did not activate lymphocytes or alter stem cell tumor-homing ability. ${ }^{99}$ Stephan et al. also found maleimide-functionalized NPs rapidly relocated to Tcell/tumor cell contact zone following antigen recognition (Figure 3D). ${ }^{71}$

Covalent coupling typically exerts stronger binding than ligand-receptor interactions to avoid drug vehicle detachment during cell migration. Versatile conjugation chemistry enables exclusively covalent reactions with amino or thiol groups that 
Table 2. Summary of Current Drug Vehicle Encapsulation/Conjugation Methods for Different Cell-Mediated Drug Delivery Systems and Their Targeted Applications

\begin{tabular}{|c|c|c|c|c|c|c|}
\hline \multicolumn{2}{|c|}{ pathway } & mechanism & cell type & drug/particles & target & ref \\
\hline \multirow[t]{13}{*}{$\begin{array}{l}\text { unmodified } \\
\text { cells }\end{array}$} & \multirow[t]{6}{*}{ endocytosis } & \multirow[t]{5}{*}{ endocytosis } & $\begin{array}{l}\text { monocyte, } \\
\text { macrophage }\end{array}$ & $\begin{array}{l}\text { (IgG/albumin coated) SPIO } \\
\text { NPs, }\end{array}$ & lymphoid tissues & 49 \\
\hline & & & $\begin{array}{l}\text { monocyte, } \\
\text { macrophage }\end{array}$ & Au nanoshells & BBB and hypoxia & 53,54 \\
\hline & & & macrophage & liposomal doxorubicin & lung cancer & 50 \\
\hline & & & macrophage & $\begin{array}{l}\text { catalyze- polyethylenimine- } \\
\text { poly(ethylene glycol) }\end{array}$ & parkinson's disease & 52 \\
\hline & & & macrophage & indinavir NPs & HIV-1 & 115 \\
\hline & & antiendocytosis & macrophage & $\begin{array}{l}\text { polyelectrolyte multilayer-based } \\
\text { disks }\end{array}$ & $\begin{array}{l}\text { macrophage associated } \\
\text { diseases }\end{array}$ & 65 \\
\hline & \multirow[t]{5}{*}{$\begin{array}{l}\text { ligand-receptor } \\
\text { binding }\end{array}$} & hyaluronic acid (HA)-CD44 & $\begin{array}{l}\mathrm{B} \text { and } \mathrm{T} \\
\text { lymphocyte }\end{array}$ & polyelectrolyte multilayer & ICAM-coated surface & $62-64$ \\
\hline & & & macrophage & $\begin{array}{l}\text { poly(ethylene glycol) } \\
\text { methacrylate-HA nanogel }\end{array}$ & $\begin{array}{l}\text { liver and spleen macrophage- } \\
\text { associated diseases }\end{array}$ & 66 \\
\hline & & antibody-CD73 and CD90 & MSC & $\begin{array}{l}\text { doxorubicin-silica nanorattles- } \\
\text { antibody }\end{array}$ & glioma tumor & 67 \\
\hline & & $\begin{array}{l}\text { antibody-complement receptor } \\
\text { type } 1\end{array}$ & $\mathrm{RBC}$ & $\begin{array}{l}\text { tissue-type plasminogen } \\
\text { activator-antibody }\end{array}$ & thromboprophylaxis & 68 \\
\hline & & peptide (ERY1)-glycophorin A & $\mathrm{RBC}$ & antigen ovalbumin-ERY1 & $\mathrm{T}$ cells & 70 \\
\hline & \multirow{2}{*}{$\begin{array}{l}\text { covalent } \\
\text { conjugation }\end{array}$} & $\mathrm{NHS}-\mathrm{NH}_{3}$ & $\mathrm{RBC}$ & hyperbranched polyglycerols & RES-related organs & 98 \\
\hline & & maleimide-thiol & T cell, MSC & liposome-coated NPs & prostate cancer, lymphoma & 71,99 \\
\hline \multirow[t]{2}{*}{$\begin{array}{l}\text { physical } \\
\text { modification }\end{array}$} & $\begin{array}{l}\text { hypotonic } \\
\text { hemolysis }\end{array}$ & membrane flexibility & $\mathrm{RBC}$ & peptide nucleic acids & macrophages & 88 \\
\hline & electroporation & $\begin{array}{l}\text { temporary dysfunctions of } \\
\text { membrane semipermeability }\end{array}$ & $\mathrm{RBC}$ & $\begin{array}{l}\text { alcohol dehydrogenase and } \\
\text { aldehyde dehydrogenase }\end{array}$ & RES-related organs & 116 \\
\hline \multirow{6}{*}{$\begin{array}{l}\text { chemical } \\
\text { modification }\end{array}$} & biotinylation & avidin-biotin bridges & hMSC & NeutrAvidin-coated NPs & liver tumor & 103 \\
\hline & & & $\mathrm{RBC}$ & thrombolytics agent & thrombosis & 104,105 \\
\hline & click chemistry & $\begin{array}{l}\text { strain-promoted azide-alkyne } \\
\text { cycloaddition }\end{array}$ & macrophage & polyamidoamine dendrimers & & 98 \\
\hline & transduction & genetic transfer via viral vectors & T cell, MSC & oncolytic virus & myeloma ovarian, carcinoma & 76,77 \\
\hline & transfection & $\begin{array}{l}\text { genetic transfer via nonviral } \\
\text { vectors }\end{array}$ & MSC & TRAILs & lung cancer metastases & 78 \\
\hline & & & MSC & SPIO@AuNPs & head and neck cancer & 79 \\
\hline
\end{tabular}

are naturally expressed on cells. These covalent bindings help anchoring drug carriers on the surfaces of cells, which have advantages over engulfing inside cells in terms of cellular safety and drug protection.

Biotinylation. Biotin is a water-soluble vitamin that has a high affinity for avidin and streptavidin proteins. ${ }^{100}$ Biotinylated cells can be conjugated with various proteins, enzymes, and NPs without compromising their viability and biological activities. NHS ester-activated biotins are widely accepted biotinylation reagents that can introduce biotins on living cell membranes that contain primary amino groups. ${ }^{101,102}$ NHS esters form stable amide bonds with primary amino groups in buffers within a few hours at room temperature, which can be tolerated by most cells. NeutrAvidin-coated NPs were anchored on the biotinylated membranes of human mesenchymal stem cells (hMSCs) for up to 2 days, whereas a certain amount of NPs were observed within the cytoplasm of hMSCs possibly resulting from the membrane recognition of NPs. ${ }^{103}$ hMSCs maintained the tumor-homing capability after nanoparticle attachment. ${ }^{103}$ RBCs were also coupled with a thrombolytics agent on their surface via avidin-biotin bridges, serving as Trojan horses for prophylactic fibrinolysis. ${ }^{104,105}$ With increasing attention to cell surface biotinylation, additional biotinylation reagents have been developed to target different functional groups such as sulfhydryls, carboxyls, and carbohydrates. This diversity provides multiple choices in terms of surface modification of circulating cells to bind and load drugs or NPs.
Click Chemistry. "Click" chemistry represents a rapid, selective, and high-yielding bio-orthogonal reaction that is also capable of immobilizing materials on cell surfaces. ${ }^{106}$ Numerous click chemistry strategies have been recently developed for living cells, including copper(I)-catalyzed azide-alkyne (CuAAC), strain-promoted azide-alkyne cycloaddition (SPAAC), thiol-ene, Diels-Alder, and pseudo-click reactions. Unlike many traditional synthetic routes, click reactions take place in water solution at physiological $\mathrm{pH}$ $(6-8)$ and temperature $\left(37^{\circ} \mathrm{C}\right)$ without toxic byproducts, which are ideal platforms for loading drug vehicles onto circulating cells. ${ }^{107,108}$ To improve the binding efficiency, abiotic functional groups are initially introduced onto cells allowing counter groups on drugs and particles to undergo click chemistry. To date, CuAAC, SPAAC, and thiol-ene reactions have been applied to click living cells ${ }^{109}$

$\mathrm{CuAAC}$ and SPAAC are $[3+2]$ azide-alkyne cycloaddition in the context of Staudinger Ligation. ${ }^{110}$ Azide groups, which are naturally absent on mammalian cell surfaces, need to be introduced to enable click reactions between cells and therapeutics via biosynthesis. Cell glycosylation, which is also called carbohydrate reaction, provides accessibility to incorporate azido sugars onto membranes through sialic acid. Generally, azido sugars can be metabolically inserted into the cell membranes after $24-48 \mathrm{~h}$ of incubation. The azidefunctionalized cells subsequently undergo reaction with drugs or NPs containing activated alkyne groups. The reaction, however, is thermodynamically favorable at high temperature or 
pressure, which is not applicable in living systems. Thus, CuAAC utilizes $\mathrm{Cu}^{+}$catalyst to accelerate the reaction within $30 \mathrm{~min}$ at physiological conditions. ${ }^{111}$ Unfortunately, the cytotoxic $\mathrm{Cu}^{+}$catalyst limits the in vitro and in vivo applications. Importantly, studies have indicated that alkyne activation can be achieved by introducing ring strain, namely SPAAC, which is a $\mathrm{Cu}$-free click chemistry for selective biomolecule labeling in living organisms based on different glycosylation degrees between abnormal and normal cells. ${ }^{107,112}$ $\mathrm{Xu}$ et al. immobilized highly branched polyamidoamine dendrimers on azido-modified macrophage surfaces by SPAAC copper-free click chemistry. ${ }^{113}$ Cell motility and its common stress-activated signaling pathways, including AKT, p65, and p38, have no significant alteration during the cellnanoparticle hybridization process. An alternative approach to employ click chemistry is the thiol-ene reaction. Briefly, methacryloyl groups can be incorporated onto cell surfaces through a glycosylation pathway and then clicked with a thiolterminal polymer. The thiol-ene reaction was explored on clicking cancer cells. ${ }^{114}$ Despite few developments on clicking circulating cells, click chemistry has shown potential in delivering therapeutics and imaging agents. A shortcoming of linking cell and therapeutics by click chemistry is that relatively complicated surface chemistry is required.

\section{TARGETING STRATEGIES OF CELL-MEDIATED DRUG DELIVERY}

Once drug vehicles are assembled with circulating cells either in vitro or in vivo, the complexes can travel and diffuse within the blood circulation and further navigate to the desired targets (Table 2). By taking advantages of carrier cells' intrinsic capabilities, controlled drug/particle delivery to specific disease sites can be achieved (Figure 4.). In this section, we will review the existing circulating cell-based targeting strategies for various objectives.

Passive Targeting: RES/Non-RES Targeting. The first rational living cell-based targeted drug delivery strategy is passive targeting, including RES and non-RES effects. For example, as RBCs age, they are recognized by the RES and subsequently undergo cell membrane lysis by lysosomal enzymes and hemoglobin degradation, and eventually lose

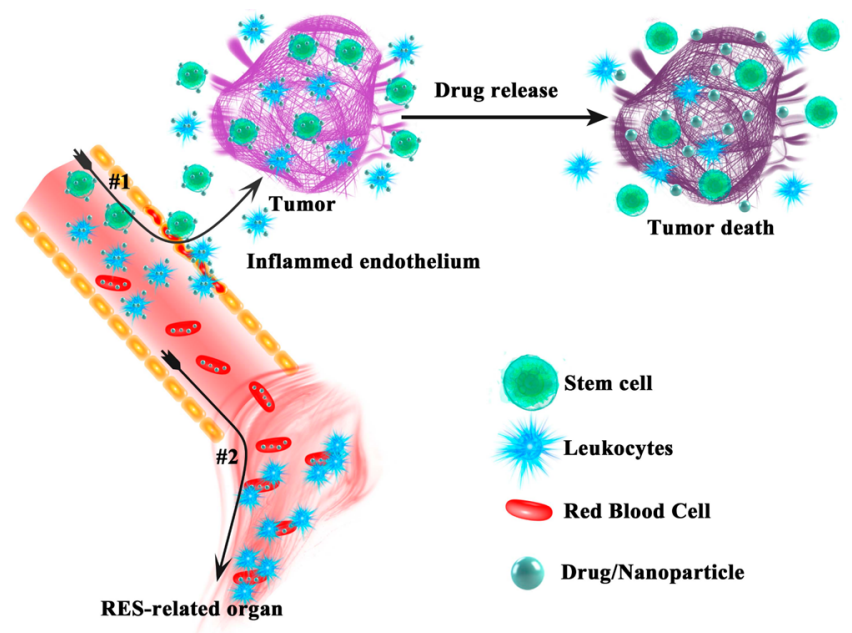

Figure 4. Illustration of circulating cell-mediated targeting and drug delivery pathways. \#1: living targeting to disease sites via leukocytes and stem cells. \#2: RES targeting via RBCs. their flexibility, integrity, and functionality. ${ }^{117,118}$ Taking advantage of the metabolic pathways in physiologic conditions, RBCs-based drug/particle complexes can easily and efficiently target RES-related regions such as liver, spleen, and bone marrow. RES clearance can be accelerated by altering the properties of RBCs during drug-loading processes in order to enhance the targeting efficiency. This strategy has been demonstrated in drug delivery for more than 30 years. ${ }^{117,119}$ Its applications range from RES organ targeting to targeting specific cell types, including hepatic Kupffer cells, alveolar macrophages, peritoneal macrophages, and peripheral blood monocytes, for delivering drugs to treat diverse diseases such as infections, inflammations, leukemia, and cancers. ${ }^{120-125}$

However, rapid clearance by the RES significantly limits the employment of RBC carriers in non-RES targeting. To address this problem, researchers have developed several approaches to permit the survival of heterologous or even xenogeneic RBCs in the circulation. A straightforward strategy to modify RBCs is by conjugating with nonimmunogenic materials onto the surfaces of RBCs in order to generate immunocamouflaged cells. Polyethylene glycol (PEG) is a bioinert and hydrophilic polymer that is widely used for cell stealth purposes. Using the same technique, methoxy(polyethylene glycol) (mPEG) was attached on the surface of RBCs and the immunogenity of modified RBCs was adjusted by varying the surface density and chain size of the coating polymer. ${ }^{126}$ The mPEG-modified RBCs still retained normal morphology, osmotic fragility, oxygen transportation, and high cell viability, but became resistant to RES clearance with prolonged circulation time. ${ }^{127,128}$ An alternative polymer, HPG, has similar antigen "mask" effects. ${ }^{98}$ HPG is a hyperbranched polymer with the capability of further modification to achieve controlled release. Furthermore, stimuli-responsive RBCs, such as ultrasoundresponsive $\mathrm{RBCs}^{129}$ and magnetic-responsive $\mathrm{RBCs},{ }^{130}$ can be directed to disease sites, providing a platform for non-RES targeting. However, cell-based passive targeting strategies are still similar to the passive targeting of bare NPs, which typically cannot reach the desired targeting and drug delivery efficiency. Additionally, RBCs are mostly used in passive targeting pathways, which are less favorable for many diseases.

Live Cell-Mediated Targeting Strategies. Many circulating cells such as neutrophils, monocytes/macrophages, and stem cells present targeting capabilities to many diseases, including cancer, wounds, and ischemic tissues. For example, tumor-homing, one of the most studied targeting mechanisms of living cells, suggests that various cells can not only sense solid tumors, but can also track circulating cancer cells in the blood flow and reach the primary and metastatic tumor sites. Targeting solid tumors, tumor microenvironments, and cancer metastases will be reviewed, respectively, here.

Leukocytes are the cells involved in immune response so they are essential for inflammation, disease development, regulation, and healing processes. The general paradigm of neutrophil and monocyte extravasation includes tethering, rolling, adhesion, crawling, and eventually transmigration. ${ }^{131,132}$ For many diseases, an injured endothelium is activated directly by pathogens or indirectly by pro-inflammation. ${ }^{133,134} \mathrm{Neu}-$ trophils are well-recognized as the first cells to be recruited by chemoattractants (e.g., platelet-activating factor, interleukin 8 , interleukin 17, formyl-methionyl-leucyl-phenylalanine, and complement component 5a), cytokines (e.g., TNF- $\alpha$ ), growth factors (e.g., granulocyte-macrophage colony-stimulating factor), and bacterial products (e.g., formylated peptides and 
lipopolysaccharide). ${ }^{135,136}$ With the increasing expression of adhesion molecules, P-selectin and E-selectin in particular, neutrophils tether and slowly roll onto the surface of the endothelium. ${ }^{137-139}$ Mediated by chemokines and adhesion molecules, neutrophils firmly attach on the endothelium and subsequently crawl toward endothelial adjunctions. ${ }^{140-143}$ Finally, neutrophils cross the endothelium, basement membrane, pericytes, and reach disease sites. ${ }^{144}$ Monocytes are also recruited by similar chemokines, cytokines, and growth factors. ${ }^{132,145}$ Afterward, monocytes differentiate into highly specialized macrophages to participate in the following immune responses. ${ }^{146}$ Similarly, lymphocytes can infiltrate tumor sites and display a series of immune responses. ${ }^{147,148}$ Therefore, the tumor-homing mechanisms of leukocytes provide active and "living" approaches for cell-mediated drug delivery. Doxorubicin (Dox) encapsulated liposome-carrying macrophages accumulated in lung tumors and released Dox after $24 \mathrm{~h}$ of administration, but a smaller amount of Dox was observed without using macrophage carries (Figure 5A). ${ }^{50}$ Adhesion molecule-associated extravasation also provides targeting options. PEM-functionalized $\mathrm{T}$ cells can migrate to ICAMcoated surface. $^{62}$ A recent study has demonstrated that RGDmodified single-walled carbon nanotubes can target monocytes and enhance the delivery efficiency of monocyte carriers via integrin mediation (Figure 5B). ${ }^{149}$

A particularly important application of leukocyte-mediated $\mathrm{drug} /$ nanoparticle delivery is the brain drug delivery across the $\mathrm{BBB}$. The BBB, which is a tight assembly of endothelium cells and astrocytes, separates the brain from the circulatory system. ${ }^{118}$ The barrier is therefore highly selective and only allows the passage of essential nutrition such as water, soluble lipid molecules, amino acids, and glucose while blocking other substances. The BBB protects the brain from harmful substances; however, it also establishes a huge obstacle for delivering therapeutic agents to the brain. Interestingly, monocytes/macrophages are able to transmigrate across the $\mathrm{BBB}$. Therefore, they can potentially serve as carriers for sheathed brain drug delivery. Bone-marrow-derived macrophages were found to be able to infiltrate into the brain and deliver nanozyme in a Parkinson's disease model. ${ }^{150}$ MRI contrast agent-labeled murine monocytes/macrophages also targeted and accumulated in rat brain tumors. ${ }^{151}$ A similar concept was applied in FluoSpheres NeutrAvidin-labeled microspheres delivered to brain metastasis of breast cancer via monocytes/macrophages (Figure $5 \mathrm{C}$ ). ${ }^{54}$

The tumor microenvironment, which involves a vast amount of cells, vessels, and stroma, is another potential target for circulating cell-mediated therapeutic delivery. Solid tumors generally contain hypoxic regions with low oxygen levels due to poor angiogenesis. Hypoxia is associated with necrosis and facilitates tumor mutation. ${ }^{152}$ Because of the lack of blood vessels, hypoxic cells are resistant to traditional drug delivery approaches. Promisingly, monocytes, tumor-associated macrophages, and tumor infiltrating lymphocytes are frequently found within tumor microenvironments including hypoxic and necrotic regions, suggesting that leucocytes could access in the depth of tumors. Choi et al. utilized monocytes/ macrophages as "Trojan horses" to deliver gold nanoshells to the hypoxic regions of cancer and their results suggested that malignant cells were completely killed within these areas, where free nanoshells could not access. ${ }^{53}$

Stem cells can also naturally migrate toward injured tissues as part of the healing process. In addition, stem cells display
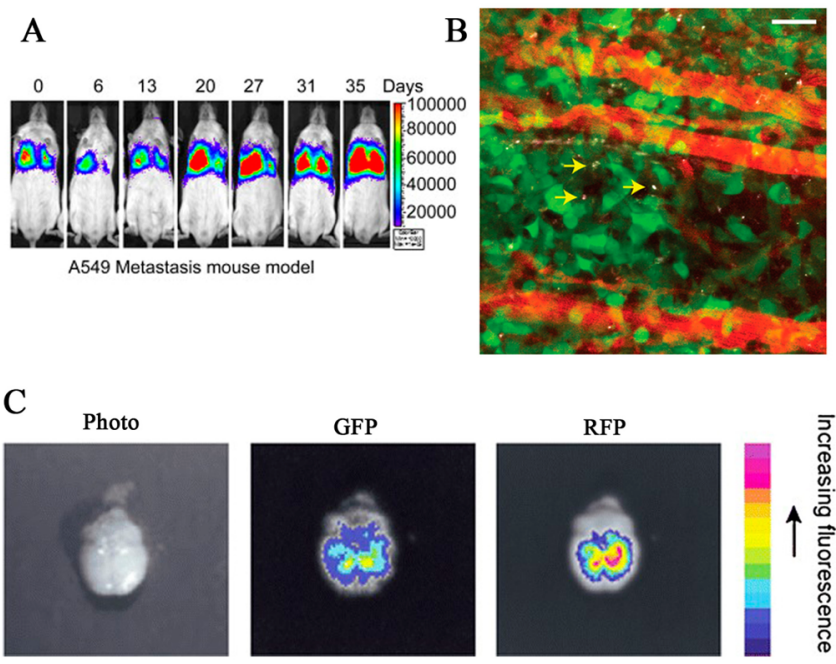

D
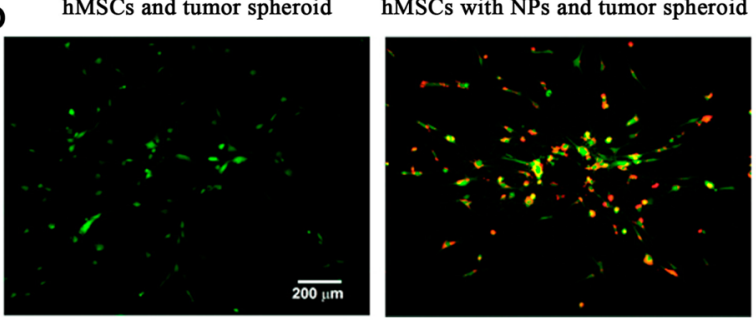

Figure 5. Cell-mediated targeting approaches to different disease sites via leukocytes and stem cells that retain their intrinsic capacities of crossing biological barriers and homing to tumor after nanoparticle assembly. (A) Bioluminescence images of macrophages carrying liposome-doxorubicin, which accumulated at lung cancer metastasis sites. $^{50}$ Reprinted with permission from ref 50. Copyright 2012 Elsevier. (B) Single-walled carbon nanotube-laden monocytes (gray) bypassed blood vessels (red) and infiltrated tumor (green) interstitium. Scale bar, $50 \mu \mathrm{m}$. ${ }^{149}$ Reprinted with permission from ref 149. Copyright 2014 Nature Publishing Group. (C) Ex vivo images of monocytes/macrophages that loaded with fluorescence labeled microspheres located within brain metastatic tumor (green) at $24 \mathrm{~h}$ postinjection in a mouse model. ${ }^{54}$ Reprinted with permission from ref 54. Copyright 2012 Springer. (D) Fluorescence images of hMSCs (green) anchored with NeutrAvidin-coated NPs (red) sensed and responded to tumor spheroid (overlaid phase-contrast image) in vitro, indicated by cell polarization. ${ }^{103}$ Reprinted with permission from ref 103. Copyright 2010 American Chemical Society.

tumor-homing and BBB-infiltrating properties. ${ }^{153}$ Emerging evidence suggest that various types of stem cells have exclusive tropism for tumors and can thus mediate drug delivery. Previous attempts have emphasized on producing a large number of therapeutic agents in situ via genetically modified stem cells. For example, interferon- $\beta$ gene transduced/transfected hMSCs preferentially accumulated in gliomas, melanomas, and pulmonary metastases, then locally released interferon- $\beta$, and induced tumor regression. ${ }^{154-156}$ In another study, neural stem cells migrated toward intracranial gliomas and delivered the oncolytic drug, 5-fluorouracil, to reduce about $80 \%$ of the tumor mass within 2 weeks. ${ }^{38}$ Although stem cellmediated gene therapy showed great outcomes, recent studies have put more attention on developing drug/biomaterial-laden cell carriers to reduce the potential risk of gene modification. NeutrAvidin nanoparticle-coated hMSCs were found be able to sense liver tumor spheroids in vitro (Figure 5D). ${ }^{103}$ MSCs surface-modified with Dox-loaded silica nanorattles also 
successfully tracked glioma cells and released Dox to kill cancer cells. ${ }^{67}$ Recently, multifunctional theranostic NPs, such as SPIO-loaded gold NPs and photosensitizer silica NPs, were successfully delivered to different tumors via MSC-mediated approaches. $^{157,158}$

Cancer cells are particularly lethal when they reach the metastatic state. Unfortunately, delivering therapeutics to metastatic circulating tumor cells (CTCs) has been a significant challenge for decades because of their scarcity in the blood circulation. CTCs are capable of leaving a primary tumor, seeding metastases in distant sites. Effective therapies that directly remove CTCs from the blood circulation have not been found yet since CTCs circulate in the bloodstream with a low concentration (average 8 cells $/ \mathrm{mL}$ ) and are difficult to detect. ${ }^{159}$ Interestingly, studies have indicated that tumor cells exhibit interactions with leukocytes and endothelial cells via adhesion molecules, which provide a platform for targeting CTCs through leukocytes. Inspired by selectin-dependent rolling along the vessel, human E-selectin, and cancer-specific TRAIL functionalized leukocytes were used to target CTCs, which displayed sialylated carbohydrate ligands for selectin under blood flow resulting in effective tumor killing outcome. ${ }^{160}$ Studies have also found that tumor cells express adhesion molecules such as intercellular adhesion molecule 1 (ICAM-1, also known as CD54) that can bind to lymphocyte function-associated antigen (LFA-1, also known as CD11a) and macrophage-1 antigen (MAC-1, also known as CD11b) in the circulation. $^{11,161}$

Therefore, circulating cells have shown promise as a powerful drug delivery system with an innate ability to detect diseases, cross biological barriers, and release drugs to disease sites. Compared to conventional drug delivery and nanomedicine, utilizing the natural ability of different cells is a completely different targeting mechanism, in which living cells act as guiders and drivers for delivering therapeutics and NPs. This strategy has also opened up new avenues for treatments of diseases that cannot be easily reached by traditional DDS.

Engineered Targeting/Binding. To maximize the targeting efficiency, engineered unnatural targeting/binding strategies have been developed for living cell-mediated DDS, allowing flexibility and diversity in binding pathways. Antibody decoration is one of the most popular techniques, by which cell carriers spontaneously search for specific antigens and even trigger the clearance of certain cells. Lipophilic anti-CD45 and anti-CD20 (Rituximab) surface-painted RBCs effectively depleted CD45 positive leukocytes and CD19+/CD20 $+/$ CD 45 + human lymphoma cells. ${ }^{162}$

An alternative approach is to use an external magnetic field to enhance the accumulation of cell carriers in targets. Magnetic nanomaterials can enable remote control of the location of drug vehicles including circulating cells by an external magnetic field. SPION NPs have been widely explored due to their biocompatibility, ease of handling, and good MRI contrast. SPIO NPs loaded RBCs successfully targeted to tumor cells under magnetic stimulation, further reducing the RES aggregation. ${ }^{163}$ The combination of molecular binding and cell-mediated drug delivery is a new and emerging field. The techniques in cellular engineering and biomaterial modifications offer significant opportunities for targeted drug and nanoparticle delivery.

\section{CONTROLLED DRUG RELEASE}

The controlled release of therapeutics is desired in medicine. ${ }^{164}$ It is even more critical for circulating cell-mediated drug delivery, because it requires not only maximum treatment effects, but also limited drug release in carrier cells. Generally, the encapsulation or conjugation of free drugs in cell carriers is not ideal due to the cytotoxicity of drugs and drug-cell interactions. Drugs are thus protected in vehicles made with various materials forming new complexes to ultimately control the payload release. In this section, strategies for controlled drug release from circulating cells will be reviewed.

Degradation Controlled Drug Release. Biodegradable polymers are the most widely used biomaterials for controlled drug release, because the release can be controlled by degradation mechanisms. Hydrolytic and enzymatic degradations are typical approaches to control drug release rates after being uptaken by cells. Abundant enzymes are located in the cytoplasm of phagocytic cells and able to facilitate the breakdown of engulfed substances. The degradation can be fine-tuned to obtain minimal release in circulating cells and release at desired disease sites. Liposomes are popular drug vehicles that have been used in many commercialized pharmaceutical formulations. Through elegant engineering designs, the desired release of drugs from liposomes can also be achieved after being delivered by living cells. For example, when liposome-Dox-loaded macrophages arrived at the tumor sites, drugs were released via macrophage death cause by leaky Dox from liposome degradation. ${ }^{50}$ Biodegradable polymeric particles, for instance, polylactic acid (PLA) NPs, have manageable degradation profiles that are ideal for controlled drug release. ${ }^{165}$ The slow degradation may ensure safety to circulating carrier cells and programmed release upon reaching disease sites. However, degradation controlled release may not achieve the ultimate safety and therapeutic effects due to the complicity of the in vivo environment and the fact that drug diffusion is also somewhat independent from material degradation. Thus, stimuli-triggered release from a smart drug delivery system can be advantageous.

Stimulated Drug Release by Cells and Local Microenvironment. Environmental responsive/smart drug release has gained much attention in recent decades in the field of drug delivery, as payloads can be discharged by responding the local cellular/physiological changes, which may have resulted from disease development or inflammation. ${ }^{166,167}$ It is also promising to combine the cell-mediated "live" targeting mechanism with a "smart" releasing mechanism. For instance, glutathione can reduce disulfide bonds and is available for responsive drug release within cytoplasm. An acute lymphoblastic leukemia drug, L-asparaginase, was covalently conjugated with cellpenetrating peptides (CPP) via disulfide linkages, followed by the encapsulation by RBCs without any membrane alteration. ${ }^{168}$ The disulfide linkage disassociation occurred within the cytoplasm of RBCs, which contains glutathione, and resulted in the release of $\mathrm{L}$-asparaginase release. $\mathrm{RBCs}$ spontaneously triggered drug release in the absence of external interventions, but underwent apoptosis to release the drug out of the cells. ${ }^{168}$

Another pathway to facilitate drug release from cell carriers is discharging the drug-loaded nanoparticle as a whole. Generally, cells retain their equilibrium via constantly engulfing foreign substances and liberating engulfed particles. In contrast to endocytosis, exocytosis allows secreting drug vehicles out of 
cells, as a potential approach for nanoparticle delivery. In a recent study, bone-marrow-derived macrophages internalized catalase/polyethylenimine-PEG nanozymes within 40-60 min and sustained released the cargos for 4-5 days. ${ }^{150}$ And the release rate can be enhanced by phorbol myristate acetate treatment. ${ }^{52}$ ALthough the integrity of cell carriers can be maintained after the drug is released by taking advantages of exocytosis, the hemostasis may occur and the chances of off-site targeting may rise.

External Stimulation Triggered Drug Release. External stimulation is an attractive alternative to trigger the localized release of therapeutic agents after reaching the disease sites, if the local microenvironmental change is not available or not strong enough. Particularly, stimuli-responsive polymers have unique characteristics that respond to small changes in the microenvironment and are therefore being widely used in smart drug delivery. ${ }^{166,169}$ Drugs are securely protected by polymeric vehicles until external stimulation, which ensures rapid, transient and precise drug release is applied. Again, combining external stimuli-responsive release with living cell-mediated targeting is a potential area to be explored.

Until now, numerous smart drug vehicles have been developed that respond to external stimuli, such as temperature, light, pressure, light, or ultrasound. In some cases, drugs can be released by multiple stimulations to ensure an on-demand administration. For example, Swiston et al. functionalized lymphocytes with PEM coatings by combining both $\mathrm{pH}$ sensitive and temperature-sensitive polymers. And these lymphocytes were able to regulate drug release by dual factors. ${ }^{62}$ Overall, stimuli-responsive drug release can be crucial for a cell-based DDS, even more significant than for the conventional DDS.

\section{CONCLUSIONS AND FUTURE PROSPECTS}

Circulating cell-mediated drug delivery has emerged as a new concept that focuses on the targeted delivery of therapeutics by living cells instead of passive factors or surface markers. A summary of comparison between conventional DDS and cellmediated DDS is shown in Table 3. As we have discussed, various cell types in the circulation, including RBCs, leukocytes, and stem cells, are available for carrying drugs and particles to targeted diseases. Generally, three steps are considered in terms of design strategies: drugs/particles loading by cell carriers, cell carriers targeted to desired locations, and controlled drug release/treatment. Compared to traditional targeted drug delivery and nanomedicine strategies, additional factors must be considered for cell-mediated drug delivery. The drugs/ particles must not be toxic to the cell carrier and should prevent cell alteration after drug loading. Thus, more attention has been paid to anchoring therapeutics on the surface of living cells. Certainly, high drug/particle loading or binding efficiency is favorable. We have elaborated on the feasibility and variety of cell targeting pathways to target different diseases. Rational selection of appropriate cells is necessary to achieve high targeting efficiency for new cell-mediated drug delivery system. Finally, it is imperative to employ a controlled drug releasing mechanism to ensure safety and maximize therapeutic effects. New treatment methods, such as photothermal and magnetic hyperthermia therapies, can also benefit from living cell-based delivery systems. The development of suitable biomaterials and biomedical engineering techniques is particularly important in creating new and effective cell-mediated drug delivery systems.
Table 3. Comparison of Conventional DDS and CellMediated DDS

\begin{tabular}{|c|c|c|}
\hline & conventional DDS & cell-mediated DDS \\
\hline $\begin{array}{l}\text { drug } \\
\text { encapsulation }\end{array}$ & $\begin{array}{l}\text { physical or chemical } \\
\text { methods }\end{array}$ & $\begin{array}{l}\text { biological, physical or } \\
\text { chemical methods }\end{array}$ \\
\hline \multirow[t]{2}{*}{ circulating time } & $\begin{array}{l}\text { short, easy to be eliminated } \\
\text { via res system; }\end{array}$ & $\begin{array}{l}\text { longer, cells are capable of } \\
\text { circulating in blood }\end{array}$ \\
\hline & $\begin{array}{l}\text { stealth coating generally } \\
\text { used }\end{array}$ & \\
\hline \multirow[t]{4}{*}{ targeting } & $\begin{array}{l}\text { decorated with targeting } \\
\text { ligands and molecules; }\end{array}$ & natural homing ability; \\
\hline & $\begin{array}{l}\text { mostly depend on EPR } \\
\text { effects; }\end{array}$ & possess cell signaling; \\
\hline & $\begin{array}{l}\text { difficult in transmembrane } \\
\text { penetration; }\end{array}$ & $\begin{array}{l}\text { penetrate through } \\
\text { biological barriers; }\end{array}$ \\
\hline & $\begin{array}{l}\text { access to vascular areas } \\
\text { only }\end{array}$ & reach to nonvascular areas \\
\hline drug release & $\begin{array}{l}\text { controlled drug release via } \\
\text { diffusion, degradation or } \\
\text { external stimulation }\end{array}$ & $\begin{array}{l}\text { controlled drug release via } \\
\text { exocytosis, degradation or } \\
\text { external stimulation }\end{array}$ \\
\hline safety & $\begin{array}{l}\text { may have off-site drug } \\
\text { release }\end{array}$ & \\
\hline \multirow[t]{2}{*}{ biocompatibility } & $\begin{array}{l}\text { may cause unwanted } \\
\text { immune response; }\end{array}$ & natural biocompatibility; \\
\hline & & $\begin{array}{l}\text { may cause unwanted } \\
\text { immune response after } \\
\text { modification. }\end{array}$ \\
\hline
\end{tabular}

Although novel cell-mediated drug/nanomedicine delivery holds promises in improving diagnosis and therapeutic effects, it is debatable whether this strategy is safe enough for clinical practices. Many challenges still remain for this state-of-art approach. Generally, candidate cells are isolated and functionalized in vitro, followed by reinjection into the circulation or disease sites. Although current techniques allow effective isolation and expansion of certain cells in vitro, cell-carriers are susceptible to contamination and other risks. Alternatively, drugs and drug-engulfed vehicles can be directly injected into the circulation to bind with cell carriers in vivo. However, the drug loading efficiency may be compromised due to immune surveillance and drug vehicles' limited binding ability. Potential therapeutics leaking from the carrying cells is another concern. Additionally, a wide spectrum of cells playing multiple roles in disease development and the healing process may participate in the drug delivery procedure. Introducing cell carriers may interrupt the balance of natural physiological conditions. For example, leukocytes are attracted to inflammation sites to deliver medicine in the short term, but they can also cause chronic inflammation issues later. Because the mechanism and development of many diseases are not well understood, foreign cells with drug complexes may also exacerbate pathological conditions. In the meantime, more evidence is needed to verify the applicability of cell-mediated DDS in various diseases, including but not limited to cancers, wound healing, brain diseases, and cardiovascular diseases.

Regardless of these challenges, cell-mediated drug delivery holds great potential to revolutionize current diagnostic and medical techniques. Advances in biomaterials may open up the door to a new paradigm of DDS designs. Engineering tools for manipulating living cells and fabricating drug vehicles, such as NPs, will create efficient and intelligent targeting, releasing, and imaging strategies. Combining living circulating cells and nanotechnology will be the new direction for controlled drug delivery, while offering a powerful technique to improve overall diagnostic and therapeutic outcomes. 


\section{AUTHOR INFORMATION}

\section{Corresponding Authors}

*E-mail: jxy30@psu.edu.

*E-mail: cxd23@psu.edu.

\section{Author Contributions}

${ }^{\ddagger}$ Y.S. and Z.X. contributed equally to this work. The manuscript was written through contributions of all authors. All authors have given approval to the final version of the manuscript.

Notes

The authors declare no competing financial interest.

\section{ACKNOWLEDGMENTS}

The authors are grateful for the funding support from National Institutes of Health (NIH) Awards NIBIB EB012575, NCI CA182670, and NHLBI HL118498, and National Science Foundation (NSF) Awards DMR 1313553, CMMI 1266116, and CBET-BME 1330663.

\section{ABBREVIATIONS}

DDS, drug delivery systems; NPs, nanoparticles; EPR, enhanced permeability and retention; RES, reticuloendothelial system; BBB, blood brain barrier; RBC, red blood cell; WBC, white blood cell; PMN, polymorphonuclear granulocyte; APC, antigen-presenting cell; SPIO, superparamagnetic iron oxide; PS, polystyrene; HA, hyaluronic acid; PEM, polyelectrolyte multilayer; MSC, mesenchymal stem cells; hMSC, human mesenchymal stem cells; CR1, complement receptor type 1; tPA: tissue-type plasminogen; mAb, monoclonal antibody; NHS, N-hydroxysuccinimide; HPG, hyperbranched polyglycerol; SS, succinimidyl succinate; PNAs, peptide nucleic acids; CuAAC, copper(I)-catalyzed azide-alkyne; SPAAC, strainpromoted azide-alkyne cycloaddition; OV, oncolytic virus; MPC, mesenchymal progenitor cells; TNF, transfect tumor necrosis factor; TRAIL, TNF-related apoptosis-inducing ligands; PEG, polyethylene glycol; Dox, doxorubicin; CTCs, circulating tumor cells; CPP, cell-penetrating peptide

\section{REFERENCES}

(1) Allen, T. M.; Cullis, P. R. Liposomal drug delivery systems: from concept to clinical applications. Adv. Drug Delivery Rev. 2013, 65, 3648.

(2) Parveen, S.; Misra, R.; Sahoo, S. K. Nanoparticles: a boon to drug delivery, therapeutics, diagnostics and imaging. Nanomedicine 2012, 8, 147-166.

(3) Kedar, U.; Phutane, P.; Shidhaye, S.; Kadam, V. Advances in polymeric micelles for drug delivery and tumor targeting. Nanomedicine 2010, 6, 714-729.

(4) Ashley, G. W.; Henise, J.; Reid, R.; Santi, D. V. Hydrogel drug delivery system with predictable and tunable drug release and degradation rates. Proc. Natl. Acad. Sci. U. S. A. 2013, 110, 2318-2323.

(5) Hamidi, M.; Azadi, A.; Rafiei, P. Hydrogel nanoparticles in drug delivery. Adv. Drug Delivery Rev. 2008, 60, 1638-1649.

(6) Cui, W.; Zhou, Y.; Chang, J. Electrospun nanofibrous materials for tissue engineering and drug delivery. Sci. Technol. Adv. Mater. 2010, 11, 014108.

(7) Yoo, H. S.; Kim, T. G.; Park, T. G. Surface-functionalized electrospun nanofibers for tissue engineering and drug delivery. Adv. Drug Delivery Rev. 2009, 61, 1033-1042.

(8) Prausnitz, M. R; Langer, R. Transdermal drug delivery. Nat. Biotechnol. 2008, 26, 1261-1268.

(9) Keefe, A. D.; Pai, S.; Ellington, A. Aptamers as therapeutics. Nat. Rev. Drug Discovery 2010, 9, 537-550.

(10) Torchilin, V. P. Multifunctional nanocarriers. Adv. Drug Delivery Rev. 2012, 64, 302-315.
(11) Brannon-Peppas, L.; Blanchette, J. O. Nanoparticle and targeted systems for cancer therapy. Adv. Drug Delivery Rev. 2012, 64 (Supplement), 206-212.

(12) Muro, S. Challenges in design and characterization of ligandtargeted drug delivery systems. J. Controlled Release 2012, 164, 125137.

(13) Snyder, E. L.; Dowdy, S. F. Cell penetrating peptides in drug delivery. Pharm. Res. 2004, 21, 389-393.

(14) Torchilin, V. P.; Trubetskoy, V. S. Which polymers can make nanoparticulate drug carriers long-circulating? Adv. Drug Delivery Rev. 1995, 16, 141-155.

(15) Greenwald, R. B.; Choe, Y. H.; McGuire, J.; Conover, C. D. Effective drug delivery by PEGylated drug conjugates. Adv. Drug Delivery Rev. 2003, 55, 217-250.

(16) Alexis, F.; Pridgen, E.; Molnar, L. K.; Farokhzad, O. C. Factors affecting the clearance and biodistribution of polymeric nanoparticles. Mol. Pharmaceutics 2008, 5, 505-515.

(17) Fang, J.; Nakamura, H.; Maeda, H. The EPR effect: unique features of tumor blood vessels for drug delivery, factors involved, and limitations and augmentation of the effect. Adv. Drug Delivery Rev. 2011, 63, 136-151.

(18) Tatum, J. L. Hypoxia: importance in tumor biology, noninvasive measurement by imaging, and value of its measurement in the management of cancer therapy. Int. J. Radiat. Biol. 2006, 82, 699-757.

(19) Qin, J.; Yang, X.; Zhang, R. X.; Luo, Y. X.; Li, J. L.; Hou, J.; Zhang, C.; Li, Y. J.; Shi, J.; Lu, L.; Wang, J. X.; Zhu, W. L. Monocyte mediated brain targeting delivery of macromolecular drug for the therapy of depression. Nanomedicine 2014, 11, 391-400.

(20) Berezina, T. L.; Zaets, S. B.; Morgan, C.; Spillert, C. R.; Kamiyama, M.; Spolarics, Z.; Deitch, E. A.; Machiedo, G. W. Influence of storage on red blood cell rheological properties. J. Surg. Res. 2002, $102,6-12$.

(21) Muzykantov, V. R. Drug delivery by red blood cells: vascular carriers designed by mother nature. Expert Opin. Drug Delivery 2010, 7, 403-427.

(22) Hollowell, J. G.; van Assendelft, O. W.; Gunter, E. W.; Lewis, B. G.; Najjar, M.; Pfeiffer, C., Hematological and Iron-Related AnalytesReference Data for Persons Aged 1 Year and Over: United States, 1988-94. In Vital Health Stat 11; United States Bureau of the Census: Washington, D.C., 2005; pp 1-156.

(23) Amulic, B.; Cazalet, C.; Hayes, G. L.; Metzler, K. D.; Zychlinsky, A. Neutrophil function: from mechanisms to disease. Annu. Rev. Immunol. 2012, 30, 459-489.

(24) Smith, J. A. Neutrophils, host defense, and inflammation: a double-edged sword. J. Leukoc. Biol. 1994, 56, 672-686.

(25) Pillay, J.; den Braber, I.; Vrisekoop, N.; Kwast, L. M.; de Boer, R. J.; Borghans, J. A. M.; Tesselaar, K.; Koenderman, L. In vivo labeling with $2 \mathrm{H} 2 \mathrm{O}$ reveals a human neutrophil lifespan of 5.4 days. Blood 2010, 116, 625-627.

(26) Adams, D. H.; Rlloyd, A. Chemokines: leucocyte recruitment and activation cytokines. Lancet 1997, 349, 490-495.

(27) McGuinness, C.; Humphries, J.; Waltham, M.; Burnand, K.; Collins, M.; Smith, A. Recruitment of labelled monocytes by experimental venous thrombi. Thromb. Haemostasis 2001, 85, 10181024.

(28) Bingle, L.; Brown, N. J.; Lewis, C. E. The role of tumourassociated macrophages in tumour progression: implications for new anticancer therapies. J. Pathol. 2002, 196, 254-265.

(29) Sica, A.; Allavena, P.; Mantovani, A. Cancer related inflammation: the macrophage connection. Cancer Lett. 2008, 267, 204-215.

(30) Kunkel, E. J.; Butcher, E. C. Chemokines and the tissue-specific migration of lymphocytes. Immunity 2002, 16, 1-4.

(31) Sakaguchi, S.; Yamaguchi, T.; Nomura, T.; Ono, M. Regulatory $\mathrm{T}$ cells and immune tolerance. Cell 2008, 133, 775-787.

(32) Mauri, C.; Bosma, A. Immune regulatory function of B cells. Annu. Rev. Immunol. 2012, 30, 221-241.

(33) Wagers, A. J.; Weissman, I. L. Plasticity of adult stem cells. Cell 2004, 116, 639-648. 
(34) Bianco, P.; Robey, P. G. Stem cells in tissue engineering. Nature 2001, 414, 118-121.

(35) Kim, S. U.; de Vellis, J. Stem Cell-Based Cell Therapy in Neurological Diseases: A Review. J. Neurosci. Res. 2009, 87, 21832200.

(36) Reagan, M. R; Kaplan, D. L. Concise Review: Mesenchymal Stem Cell Tumor-Homing: Detection Methods in Disease Model Systems. Stem Cells 2011, 29, 920-927.

(37) Tu, S.-M.; Lin, S.-H.; Logothetis, C. J. Stem-cell origin of metastasis and heterogeneity in solid tumours. Lancet Oncol. 2002, 3, $508-513$.

(38) Aboody, K. S.; Brown, A.; Rainov, N. G.; Bower, K. A.; Liu, S.; Yang, W.; Small, J. E.; Herrlinger, U.; Ourednik, V.; Black, P. M. Neural stem cells display extensive tropism for pathology in adult brain: Evidence from intracranial gliomas. Proc. Natl. Acad. Sci. U.S.A. 2000, 97, 12846-12851.

(39) Pastan, I.; Willingham, M. C. The pathway of endocytosis. In Endocytosis; Springer: New York, 1985; pp 1-44.

(40) Canton, I.; Battaglia, G. Endocytosis at the nanoscale. Chem. Soc. Rev. 2012, 41, 2718-2739.

(41) Ben-Bassat, I.; Bensch, K. G.; Schrier, S. L. Drug-induced erythrocyte membrane internalization. J. Clin. Invest. 1972, 51, 1833.

(42) Ginn, F. L.; Hochstein, P.; Trump, B. F. Membrane Alterations in Hemolysis: Internalization of Plasmalemma Induced by Primaquine. Science 1969, 164, 843-845.

(43) Gopal, V.; Kumar, A. R.; Usha, N.; Karthik, A.; Udupa, N. Effective drug targeting by erythrocytes as carrier systems. Curr. Trends Biotechnol. Pharm. 2007, 1, 18-33.

(44) Matovcik, L. M.; Junga, I. G.; Schrier, S. L. Drug-induced endocytosis of neonatal erythrocytes. Blood 1985, 65, 1056-1063.

(45) Ben-Bassat, I.; Bensch, K. G.; Schrier, S. L. Drug-induced erythrocyte membrane internalization. J. Clin. Invest. 1972, 51, 18331844.

(46) Schrier, S. L.; Zachowski, A.; Devaux, P. F. Mechanisms of amphipath-induced stomatocytosis in human erythrocytes. Blood 1992, 79, 782-786.

(47) Aderem, A.; Underhill, D. M. Mechanisms of phagocytosis in macrophages. Annu. Rev. Immunol. 1999, 17, 593-623.

(48) Owens, D. E., III; Peppas, N. A. Opsonization, biodistribution, and pharmacokinetics of polymeric nanoparticles. Int. J. Pharm. 2006, 307, 93-102.

(49) Beduneau, A.; Ma, Z.; Grotepas, C. B.; Kabanov, A.; Rabinow, B. E.; Gong, N.; Mosley, R. L.; Dou, H.; Boska, M. D.; Gendelman, H. E. Facilitated Monocyte-Macrophage Uptake and Tissue Distribution of Superparmagnetic Iron-Oxide Nanoparticles. PLoS One 2009, 4, e4343.

(50) Choi, J.; Kim, H.-Y.; Ju, E. J.; Jung, J.; Park, J.; Chung, H.-K.; Lee, J. S.; Lee, J. S.; Park, H. J.; Song, S. Y.; Jeong, S.-Y.; Choi, E. K. Use of macrophages to deliver therapeutic and imaging contrast agents to tumors. Biomaterials 2012, 33, 4195-4203.

(51) Nowacek, A. S.; Miller, R. L.; McMillan, J.; Kanmogne, G.; Kanmogne, M.; Mosley, R. L.; Ma, Z.; Graham, S.; Chaubal, M.; Werling, J. NanoART synthesis, characterization, uptake, release and toxicology for human monocyte-macrophage drug delivery. Nanomedicine 2009, 4, 903-917.

(52) Batrakova, E. V.; Li, S.; Reynolds, A. D.; Mosley, R. L.; Bronich, T. K.; Kabanov, A. V.; Gendelman, H. E. A macrophage-nanozyme delivery system for Parkinson's disease. Bioconjugate Chem. 2007, 18, 1498-1506.

(53) Choi, M.-R.; Stanton-Maxey, K. J.; Stanley, J. K.; Levin, C. S.; Bardhan, R.; Akin, D.; Badve, S.; Sturgis, J.; Robinson, J. P.; Bashir, R. A cellular Trojan Horse for delivery of therapeutic nanoparticles into tumors. Nano Lett. 2007, 7, 3759-3765.

(54) Choi, M.-R.; Bardhan, R.; Stanton-Maxey, K. J.; Badve, S.; Nakshatri, H.; Stantz, K. M.; Cao, N.; Halas, N. J.; Clare, S. E. Delivery of nanoparticles to brain metastases of breast cancer using a cellular Trojan horse. Cancer Nanotechnol. 2012, 3, 47-54.

(55) Doshi, N.; Mitragotri, S. Macrophages Recognize Size and Shape of Their Targets. PLoS One 2010, 5, e10051.
(56) Champion, J.; Walker, A.; Mitragotri, S. Role of Particle Size in Phagocytosis of Polymeric Microspheres. Pharm. Res. 2008, 25, 18151821.

(57) Champion, J. A.; Mitragotri, S. Role of target geometry in phagocytosis. Proc. Natl. Acad. Sci. U. S. A. 2006, 103, 4930-4934.

(58) Beningo, K. A.; Wang, Y.-1. Fc-receptor-mediated phagocytosis is regulated by mechanical properties of the target. J. Cell Sci. 2002, 115, 849-856.

(59) Fujiwara, M.; Baldeschwieler, J. D.; Grubbs, R. H. Receptormediated endocytosis of poly(acrylic acid)-conjugated liposomes by macrophages. Biochim. Biophys. Acta, Biomembr. 1996, 1278, 59-67.

(60) Juliano, R. L.; Stamp, D. The effect of particle size and charge on the clearance rates of liposomes and liposome encapsulated drugs. Biochem. Biophys. Res. Commun. 1975, 63, 651-658.

(61) Champion, J.; Mitragotri, S. Shape Induced Inhibition of Phagocytosis of Polymer Particles. Pharm. Res. 2009, 26, 244-249.

(62) Swiston, A. J.; Cheng, C.; Um, S. H.; Irvine, D. J.; Cohen, R. E.; Rubner, M. F. Surface functionalization of living cells with multilayer patches. Nano Lett. 2008, 8, 4446-4453.

(63) Vasconcellos, F. C.; Swiston, A. J.; Beppu, M. M.; Cohen, R. E.; Rubner, M. F. Bioactive polyelectrolyte multilayers: Hyaluronic acid mediated B lymphocyte adhesion. Biomacromolecules 2010, 11, 24072414.

(64) Swiston, A. J.; Gilbert, J. B.; Irvine, D. J.; Cohen, R. E.; Rubner, M. F. Freely Suspended Cellular "Backpacks" Lead to Cell Aggregate Self-Assembly. Biomacromolecules 2010, 11, 1826-1832.

(65) Doshi, N.; Swiston, A. J.; Gilbert, J. B.; Alcaraz, M. L.; Cohen, R. E.; Rubner, M. F.; Mitragotri, S. Cell-Based Drug Delivery Devices Using Phagocytosis-Resistant Backpacks. Adv. Mater. 2011, 23, H105H109.

(66) Fernandes Stefanello, T.; Szarpak-Jankowska, A.; Appaix, F.; Louage, B.; Hamard, L.; De Geest, B. G.; van der Sanden, B.; Nakamura, C. V.; Auzély-Velty, R. Thermoresponsive hyaluronic acid nanogels as hydrophobic drug carrier to macrophages. Acta Biomater. 2014, 10, 4750-4758.

(67) Li, L.; Guan, Y.; Liu, H.; Hao, N.; Liu, T.; Meng, X.; Fu, C.; Li, Y.; Qu, Q.; Zhang, Y.; Ji, S.; Chen, L.; Chen, D.; Tang, F. Silica Nanorattle-Doxorubicin-Anchored Mesenchymal Stem Cells for Tumor-Tropic Therapy. ACS Nano 2011, 5, 7462-7470.

(68) Zaitsev, S.; Danielyan, K.; Murciano, J.-C.; Ganguly, K.; Krasik, T.; Taylor, R. P.; Pincus, S.; Jones, S.; Cines, D. B.; Muzykantov, V. R. Human complement receptor type 1-directed loading of tissue plasminogen activator on circulating erythrocytes for prophylactic fibrinolysis. Blood 2006, 108, 1895-1902.

(69) Kontos, S.; Hubbell, J. A. Improving protein pharmacokinetics by engineering erythrocyte affinity. Mol. Pharmaceutics 2010, 7, 21417.

(70) Kontos, S.; Kourtis, I. C.; Dane, K. Y.; Hubbell, J. A. Engineering antigens for in situ erythrocyte binding induces T-cell deletion. Proc. Natl. Acad. Sci. U.S.A. 2013, 110, E60-E68.

(71) Stephan, M. T.; Stephan, S. B.; Bak, P.; Chen, J.; Irvine, D. J. Synapse-directed delivery of immunomodulators using T-cell-conjugated nanoparticles. Biomaterials 2012, 33, 5776-5787.

(72) Naldini, L.; Blömer, U.; Gallay, P.; Ory, D.; Mulligan, R.; Gage, F. H.; Verma, I. M.; Trono, D. In vivo gene delivery and stable transduction of nondividing cells by a lentiviral vector. Science 1996, 272, 263-267.

(73) Tjuvajev, J. G.; Stockhammer, G.; Desai, R.; Uehara, H.; Watanabe, K.; Gansbacher, B.; Blasberg, R. G. Imaging the expression of transfected genes in vivo. Cancer Res. 1995, 55, 6126-6132.

(74) Chiocca, E. A. Oncolytic viruses. Nat. Rev. Cancer 2002, 2, 938950.

(75) Komarova, S.; Kawakami, Y.; Stoff-Khalili, M. A.; Curiel, D. T.; Pereboeva, L. Mesenchymal progenitor cells as cellular vehicles for delivery of oncolytic adenoviruses. Mol. Cancer Ther. 2006, 5, 755766.

(76) Pereboeva, L.; Komarova, S.; Mikheeva, G.; Krasnykh, V.; Curiel, D. T. Approaches to utilize mesenchymal progenitor cells as cellular vehicles. Stem Cells 2003, 21, 389-404. 
(77) Ong, H. T.; Hasegawa, K.; Dietz, A. B.; Russell, S. J.; Peng, K. $\mathrm{W}$. Evaluation of $\mathrm{T}$ cells as carriers for systemic measles virotherapy in the presence of antiviral antibodies. Gene Ther. 2006, 14, 324-333.

(78) Hu, Y. L.; Huang, B.; Zhang, T. Y.; Miao, P. H.; Tang, G. P.; Tabata, Y.; Gao, J. Q. Mesenchymal stem cells as a novel carrier for targeted delivery of gene in cancer therapy based on nonviral transfection. Mol. Pharmaceutics 2012, 9, 2698-2709.

(79) Melancon, M. P.; Lu, W.; Zhong, M.; Zhou, M.; Liang, G.; Elliott, A. M.; Hazle, J. D.; Myers, J. N.; Li, C.; Jason Stafford, R. Targeted multifunctional gold-based nanoshells for magnetic resonance-guided laser ablation of head and neck cancer. Biomaterials 2011, 32, 7600-7608.

(80) Huang, D.-M.; Hsiao, J.-K.; Chen, Y.-C.; Chien, L.-Y.; Yao, M.; Chen, Y.-K.; Ko, B.-S.; Hsu, S.-C.; Tai, L.-A.; Cheng, H.-Y.; Wang, S.W.; Yang, C.-S.; Chen, Y.-C. The promotion of human mesenchymal stem cell proliferation by superparamagnetic iron oxide nanoparticles. Biomaterials 2009, 30, 3645-3651.

(81) Sanz, S.; Lizano, C.; Luque, J.; Pinilla, M. In vitro and in vivo study of glutamate dehydrogenase encapsulated into mouse erythrocytes by a hypotonic dialysis procedure. Life Sci. 1999, 65, 2781-9.

(82) Kwant, W.; Seeman, P. The erythrocyte ghost is a perfect osmometer. J. Gen. Physiol. 1970, 55, 208-219.

(83) DeLoach, J.; Droleskey, R.; Andrews, K. Encapsulation by hypotonic dialysis in human erythrocytes: a diffusion or endocytosis process. Biotechnol. Appl. Biochem. 1991, 13, 72-82.

(84) Deloach, J. R. Carrier erythrocytes. Med. Res. Rev. 1986, 6, 487504.

(85) De Flora, A.; Zocchi, E.; Guida, L.; Polvani, C.; Benatti, U. Conversion of encapsulated 5-fluoro- $2^{\prime}$-deoxyuridine 5 -monophosphate to the antineoplastic drug 5-fluoro-2'-deoxyuridine in human erythrocytes. Proc. Natl. Acad. Sci. U.S.A. 1988, 85, 3145-9.

(86) Alvarez, F. J.; Jordan, J. A.; Herraez, A.; Diez, J. C.; Tejedor, M. C. Hypotonically loaded rat erythrocytes deliver encapsulated substances into peritoneal macrophages. J. Biochem. 1998, 123, 233-9.

(87) Pérez, M. T.; Alvarez, F. J.; García-Pérez, A.-I.; Lucas, L.; Tejedor, M. C.; Sancho, P. Heterogeneity of hypotonically loaded rat erythrocyte populations as detected by counter-current distribution in aqueous polymer two-phase systems. J. Chromatogr., Biomed. Sci. Appl. 1996, 677, 45-51.

(88) Chiarantini, L.; Cerasi, A.; Fraternale, A.; Andreoni, F.; Scarí, S.; Giovine, M.; Clavarino, E.; Magnani, M. Inhibition of Macrophage iNOS by Selective Targeting of Antisense PNA $\dagger$. Biochemistry 2002, $41,8471-8477$.

(89) Deloach, J.; Ihler, G. A dialysis procedure for loading erythrocytes with enzymes and lipids. Biochim. Biophys. Acta, Gen. Subj. 1977, 496, 136-45.

(90) Foroozesh, M.; Hamidi, M.; Zarrin, A.; Mohammadi-Samani, S.; Montaseri, H. Preparation and in-vitro characterization of tramadolloaded carrier erythrocytes for long-term intravenous delivery. $J$. Pharm. Pharmacol. 2011, 63, 322-332.

(91) Weaver, J. C. Electroporation of biological membranes from multicellular to nano scales. IEEE Trans. Dielectr. Electr. Insul. 2003, 10, 754-768.

(92) Tsong, T. Y. Electroporation of cell membranes. Biophys. J. 1991, 60, 297-306.

(93) Flynn, G.; Hackett, T. J.; McHale, L.; McHale, A. P. Encapsulation of the thrombolytic enzyme, brinase, in photosensitized erythrocytes: a novel thrombolytic system based on photodynamic activation. J. Photochem. Photobiol., B 1994, 26, 193-196.

(94) Mangal, P. C.; Kaur, A. Electroporation of red blood cell membrane and its use as a drug carrier system. Indian J. Biochem. Biophys. 1991, 28, 219-21.

(95) Lizano, C.; Perez, M. T.; Pinilla, M. Mouse erythrocytes as carriers for coencapsulated alcohol and aldehyde dehydrogenase obtained by electroporation in vivo survival rate in circulation, organ distribution and ethanol degradation. Life Sci. 2001, 68, 2001-16.
(96) Chen, I.; Howarth, M.; Lin, W.; Ting, A. Y. Site-specific labeling of cell surface proteins with biophysical probes using biotin ligase. Nat. Methods 2005, 2, 99-104.

(97) Ferguson, M. A.; Williams, A. F. Cell-surface anchoring of proteins via glycosyl-phosphatidylinositol structures. Annu. Rev. Biochem. 1988, 57, 285-320.

(98) Rossi, N. A. A.; Constantinescu, I.; Kainthan, R. K.; Brooks, D. E.; Scott, M. D.; Kizhakkedathu, J. N. Red blood cell membrane grafting of multi-functional hyperbranched polyglycerols. Biomaterials 2010, 31, 4167-4178.

(99) Stephan, M. T.; Moon, J. J.; Um, S. H.; Bershteyn, A.; Irvine, D. $\mathrm{J}$. Therapeutic cell engineering with surface-conjugated synthetic nanoparticles. Nat. Med. 2010, 16, 1035-1041.

(100) Diamandis, E. P.; Christopoulos, T. K. The biotin-(strept) avidin system: principles and applications in biotechnology. Clin. Chem. 1991, 37, 625-636.

(101) Parrott, M. B.; Adams, K. E.; Mercier, G. T.; Mok, H.; Campos, S. K.; Barry, M. A. Metabolically biotinylated adenovirus for cell targeting, ligand screening, and vector purification. Mol. Ther. 2003, 8, $688-700$.

(102) Suzuki, T.; Dale, G. L. Biotinylated erythrocytes: in vivo survival and in vitro recovery. Blood 1987, 70, 791-795.

(103) Cheng, H.; Kastrup, C. J.; Ramanathan, R.; Siegwart, D. J.; Ma, M.; Bogatyrev, S. R.; Xu, Q.; Whitehead, K. A.; Langer, R.; Anderson, D. G. Nanoparticulate cellular patches for cell-mediated tumoritropic delivery. ACS Nano 2010, 4, 625-631.

(104) Murciano, J.-C.; Medinilla, S.; Eslin, D.; Atochina, E.; Cines, D. B.; Muzykantov, V. R. Prophylactic fibrinolysis through selective dissolution of nascent clots by tPA-carrying erythrocytes. Nat. Biotechnol. 2003, 21, 891-896.

(105) Murciano, J.-C.; Higazi, A. A.-R.; Cines, D. B.; Muzykantov, V. $\mathrm{R}$. Soluble urokinase receptor conjugated to carrier red blood cells binds latent pro-urokinase and alters its functional profile. J. Controlled Release 2009, 139, 190-196.

(106) Baskin, J. M.; Bertozzi, C. R. Bioorthogonal click chemistry: Covalent labeling in living systems. QSAR Comb. Sci. 2007, 26, 12111219.

(107) Chang, P. V.; Prescher, J. A.; Sletten, E. M.; Baskin, J. M.; Miller, I. A.; Agard, N. J.; Lo, A.; Bertozzi, C. R. Copper-free click chemistry in living animals. Proc. Natl. Acad. Sci. U. S. A. 2010, 107, $1821-1826$.

(108) Kolb, H. C.; Sharpless, K. B. The growing impact of click chemistry on drug discovery. Drug Discovery Today 2003, 8, 11281137.

(109) Hong, V.; Steinmetz, N. F.; Manchester, M.; Finn, M. G. Labeling Live Cells by Copper-Catalyzed Alkyne-Azide Click Chemistry. Bioconjugate Chem. 2010, 21, 1912-1916.

(110) Prescher, J. A.; Bertozzi, C. R. Chemistry in living systems. Nat. Chem. Biol. 2005, 1, 13-21.

(111) Hein, J. E.; Fokin, V. V. Copper-catalyzed azide-alkyne cycloaddition (CuAAC) and beyond: new reactivity of copper (I) acetylides. Chem. Soc. Rev. 2010, 39, 1302-1315.

(112) Baskin, J. M.; Prescher, J. A.; Laughlin, S. T.; Agard, N. J.; Chang, P. V.; Miller, I. A.; Lo, A.; Codelli, J. A.; Bertozzi, C. R. Copper-free click chemistry for dynamic in vivo imaging. Proc. Natl. Acad. Sci. U.S.A. 2007, 104, 16793-16797.

(113) Xu, L.; Zolotarskaya, O. Y.; Yeudall, W. A.; Yang, H. Click Hybridization of Immune Cells and Polyamidoamine Dendrimers. Adv. Healthcare Mater. 2014, 3, 1430-1438.

(114) Iwasaki, Y.; Matsuno, H. Metabolic Delivery of Methacryloyl Groups on Living Cells and Cell Surface Modification via Thiol-Ene "Click" Reaction. Macromol. Biosci. 2011, 11, 1478-1483.

(115) Dou, H.; Destache, C. J.; Morehead, J. R.; Mosley, R. L.; Boska, M. D.; Kingsley, J.; Gorantla, S.; Poluektova, L.; Nelson, J. A.; Chaubal, M. Development of a macrophage-based nanoparticle platform for antiretroviral drug delivery. Blood 2006, 108, 2827-2835.

(116) Lizano, C.; Pérez, M. T.; Pinilla, M. Mouse erythrocytes as carriers for coencapsulated alcohol and aldehyde dehydrogenase obtained by electroporation: In vivo survival rate in circulation, 
organ distribution and ethanol degradation. Life Sci. 2001, 68, 20012016.

(117) Lynch, W. E.; Sartiano, G. P.; Ghaffar, A. Erythrocytes as carriers of chemotherapeutic agents for targeting the reticuloendothelial system. Am. J. Hematol. 1980, 9, 249-259.

(118) Knutson, M.; Wessling-Resnick, M. Iron metabolism in the reticuloendothelial system. Crit. Rev. Biochem. Mol. Biol. 2003, 38, 6188.

(119) Zocchi, E.; Tonetti, M.; Polvani, C.; Guida, L.; Benatti, U.; Flora, A. In vivo liver and lung targeting of adriamycin encapsulated in glutaraldehyde-treated murine erythrocytes. Biotechnol. Appl. Biochem. 1988, 10, 555-562.

(120) Mishra, P.; Jain, N. Biotinylated methotrexate loaded erythrocytes for enhanced liver uptake.'A study on the rat'. Int. J. Pharm. 2002, 231, 145-153.

(121) Crinelli, R.; Antonelli, A.; Bianchi, M.; Gentilini, L.; Scaramucci, S.; Magnani, M. Selective Inhibition of NF-kB Activation and TNF- $\alpha$ Production in Macrophages by Red Blood Cell-Mediated Delivery of Dexamethasone. Blood Cells, Mol., Dis. 2000, 26, 211-222.

(122) Deloach, J.; Peters, S.; Pinkard, O.; Glew, R.; Hiler, G. Effect of glutaraldehyde treatment on enzyme-loaded erythrocytes. Biochim. Biophys. Acta, Gen. Subj. 1977, 496, 507-515.

(123) Zocchi, E.; Tonetti, M.; Polvani, C.; Guida, L.; Benatti, U.; De Flora, A. Encapsulation of doxorubicin in liver-targeted erythrocytes increases the therapeutic index of the drug in a murine metastatic model. Proc. Natl. Acad. Sci. U.S.A. 1989, 86, 2040-2044.

(124) Kwon, Y. M.; Chung, H. S.; Moon, C.; Yockman, J.; Park, Y. J.; Gitlin, S. D.; David, A. E.; Yang, V. C. L-Asparaginase encapsulated intact erythrocytes for treatment of acute lymphoblastic leukemia (ALL). J. Controlled Release 2009, 139, 182-189.

(125) Rossi, L.; Serafini, S.; Antonelli, A.; Pierigé, F.; Carnevali, A.; Battistelli, V.; Malatesta, M.; Balestra, E.; Caliò, R.; Perno, C.-F. Macrophage depletion induced by clodronate-loaded erythrocytes. J. Drug Target 2005, 13, 99-111.

(126) Bradley, A. J.; Murad, K. L.; Regan, K. L.; Scott, M. D. Biophysical consequences of linker chemistry and polymer size on stealth erythrocytes: size does matter. Biochim. Biophys. Acta, Biomembr. 2002, 1561, 147-158.

(127) Murad, K. L.; Mahany, K. L.; Brugnara, C.; Kuypers, F. A.; Eaton, J. W.; Scott, M. D. Structural and functional consequences of antigenic modulation of red blood cells with methoxypoly (ethylene glycol). Blood 1999, 93, 2121-2127.

(128) Scott, M. D.; Murad, K. L.; Koumpouras, F.; Talbot, M.; Eaton, J. W. Chemical camouflage of antigenic determinants: Stealth erythrocytes. Proc. Natl. Acad. Sci. U.S.A. 1997, 94, 7566-7571.

(129) Price, R. J.; Skyba, D. M.; Kaul, S.; Skalak, T. C. Delivery of colloidal particles and red blood cells to tissue through microvessel ruptures created by targeted microbubble destruction with ultrasound. Circulation 1998, 98, 1264-7.

(130) Sprandel, U.; Lanz, D. J.; von Horsten, W. Magnetically responsive erythrocyte ghosts. Methods Enzymol. 1987, 149, 301-12.

(131) Kolaczkowska, E.; Kubes, P. Neutrophil recruitment and function in health and inflammation. Nat. Rev. Immunol. 2013, 13, 159-175.

(132) Schenkel, A. R.; Mamdouh, Z.; Muller, W. A. Locomotion of monocytes on endothelium is a critical step during extravasation. Nat. Immunol. 2004, 5, 393-400.

(133) Albelda, S. M.; Smith, C. W.; Ward, P. Adhesion molecules and inflammatory injury. FASEB J. 1994, 8, 504-512.

(134) Pober, J. S.; Cotran, R. S. The role of endothelial cells in inflammation. Transplantation 1990, 50, 537-544.

(135) Luster, A. D.; Alon, R.; von Andrian, U. H. Immune cell migration in inflammation: present and future therapeutic targets. Nat. Immunol. 2005, 6, 1182-1190.

(136) Sampson, A. The role of eosinophils and neutrophils in inflammation. Clin. Exp. Allergy 2000, 30, 22-27.

(137) Carlos, T. M.; Harlan, J. M. Leukocyte-endothelial adhesion molecules. Blood 1994, 84, 2068-2101.
(138) Bevilacqua, M. P. Endothelial-leukocyte adhesion molecules. Annu. Rev. Immunol. 1993, 11, 767-804.

(139) Diacovo, T.; Roth, S.; Buccola, J.; Bainton, D.; Springer, T. Neutrophil rolling, arrest, and transmigration across activated, surfaceadherent platelets via sequential action of P-selectin and the beta 2integrin CD11b/CD18. Blood 1996, 88, 146-157.

(140) Lo, S. K.; Lee, S.; Ramos, R. A.; Lobb, R.; Rosa, M.; Chi-Rosso, G.; Wright, S. D. Endothelial-leukocyte adhesion molecule 1 stimulates the adhesive activity of leukocyte integrin CR3 (CD11b/CD18, Mac1, alpha $\mathrm{m}$ beta 2) on human neutrophils. J. Exp. Med. 1991, 173, 1493-1500.

(141) von Andrian, U. H.; Chambers, J. D.; McEvoy, L. M.; Bargatze, R. F.; Arfors, K.-E.; Butcher, E. C. Two-step model of leukocyteendothelial cell interaction in inflammation: distinct roles for LECAM1 and the leukocyte beta 2 integrins in vivo. Proc. Natl. Acad. Sci. U.S.A. 1991, 88, 7538-7542.

(142) Phillipson, M.; Heit, B.; Colarusso, P.; Liu, L.; Ballantyne, C. M.; Kubes, P. Intraluminal crawling of neutrophils to emigration sites: a molecularly distinct process from adhesion in the recruitment cascade. J. Exp. Med. 2006, 203, 2569-2575.

(143) Williams, M. R.; Azcutia, V.; Newton, G.; Alcaide, P.; Luscinskas, F. W. Emerging mechanisms of neutrophil recruitment across endothelium. Trends Immunol. 2011, 32, 461-469.

(144) Ley, K.; Laudanna, C.; Cybulsky, M. I.; Nourshargh, S. Getting to the site of inflammation: the leukocyte adhesion cascade updated. Nat. Rev. Immunol. 2007, 7, 678-689.

(145) Shi, C.; Pamer, E. G. Monocyte recruitment during infection and inflammation. Nat. Rev. Immunol. 2011, 11, 762-774.

(146) Geissmann, F.; Manz, M. G.; Jung, S.; Sieweke, M. H.; Merad, M.; Ley, K. Development of Monocytes, Macrophages, and Dendritic Cells. Science 2010, 327, 656-661.

(147) Pages, F.; Galon, J.; Dieu-Nosjean, M.; Tartour, E.; SautesFridman, C.; Fridman, W. Immune infiltration in human tumors: a prognostic factor that should not be ignored. Oncogene 2009, 29, $1093-1102$.

(148) Kawakami, Y.; Eliyahu, S.; Delgado, C. H.; Robbins, P. F.; Sakaguchi, K.; Appella, E.; Yannelli, J. R.; Adema, G. J.; Miki, T.; Rosenberg, S. A. Identification of a human melanoma antigen recognized by tumor-infiltrating lymphocytes associated with in vivo tumor rejection. Proc. Natl. Acad. Sci. U.S.A. 1994, 91, 6458-6462.

(149) Smith, B. R.; Ghosn, E. E. B.; Rallapalli, H.; Prescher, J. A.; Larson, T.; Herzenberg, L. A.; Gambhir, S. S. Selective uptake of single-walled carbon nanotubes by circulating monocytes for enhanced tumour delivery. Nat. Nanotechnol. 2014, 9, 481-487.

(150) Batrakova, E. V.; Li, S.; Reynolds, A. D.; Mosley, R. L.; Bronich, T. K.; Kabanov, A. V.; Gendelman, H. E. A MacrophageNanozyme Delivery System for Parkinson's Disease. Bioconjugate Chem. 2007, 18, 1498-1506.

(151) Valable, S.; Barbier, E. L.; Bernaudin, M.; Roussel, S.; Segebarth, C.; Petit, E.; Rémy, C. In vivo MRI tracking of exogenous monocytes/macrophages targeting brain tumors in a rat model of glioma. NeuroImage 2008, 40, 973-983.

(152) Harris, A. L. Hypoxia-a key regulatory factor in tumour growth. Nature Reviews Cancer 2002, 2, 38-47.

(153) Roger, M.; Clavreul, A.; Venier-Julienne, M.-C.; Passirani, C.; Sindji, L.; Schiller, P.; Montero-Menei, C.; Menei, P. Mesenchymal stem cells as cellular vehicles for delivery of nanoparticles to brain tumors. Biomaterials 2010, 31, 8393-8401.

(154) Studeny, M.; Marini, F. C.; Champlin, R. E.; Zompetta, C.; Fidler, I. J.; Andreeff, M. Bone marrow-derived mesenchymal stem cells as vehicles for interferon- $\beta$ delivery into tumors. Cancer Res. 2002, 62, 3603-3608.

(155) Studeny, M.; Marini, F. C.; Dembinski, J. L.; Zompetta, C.; Cabreira-Hansen, M.; Bekele, B. N.; Champlin, R. E.; Andreeff, M. Mesenchymal stem cells: potential precursors for tumor stroma and targeted-delivery vehicles for anticancer agents. J. Natl. Cancer Inst. 2004, 96, 1593-1603.

(156) Nakamizo, A.; Marini, F.; Amano, T.; Khan, A.; Studeny, M.; Gumin, J.; Chen, J.; Hentschel, S.; Vecil, G.; Dembinski, J. Human 
bone marrow-derived mesenchymal stem cells in the treatment of gliomas. Cancer Res. 2005, 65, 3307-3318.

(157) Zhao, J.; Vykoukal, J.; Abdelsalam, M.; Recio-Boiles, A.; Huang, Q.; Qiao, Y.; Singhana, B.; Wallace, M.; Avritscher, R.; Melancon, M. P. Stem cell-mediated delivery of SPIO-loaded gold nanoparticles for the theranosis of liver injury and hepatocellular carcinoma. Nanotechnology 2014, 25, 405101.

(158) Cao, B.; Yang, M.; Zhu, Y.; Qu, X.; Mao, C. Stem Cells Loaded with Nanoparticles as a Drug Carrier for In Vivo Breast Cancer Therapy. Adv. Mater. 2014, $26,4627$.

(159) Allard, W. J.; Matera, J.; Miller, M. C.; Repollet, M.; Connelly, M. C.; Rao, C.; Tibbe, A. G. J.; Uhr, J. W.; Terstappen, L. W. M. M. Tumor Cells Circulate in the Peripheral Blood of All Major Carcinomas but not in Healthy Subjects or Patients With Nonmalignant Diseases. Clin. Cancer Res. 2004, 10, 6897-6904.

(160) Mitchell, M. J.; Wayne, E.; Rana, K.; Schaffer, C. B.; King, M. R. TRAIL-coated leukocytes that kill cancer cells in the circulation. Proc. Natl. Acad. Sci. U. S. A. 2014, 111, 930-935.

(161) Liang, S.; Slattery, M. J.; Wagner, D.; Simon, S. I.; Dong, C. Hydrodynamic shear rate regulates melanoma-leukocyte aggregation, melanoma adhesion to the endothelium, and subsequent extravasation. Ann. Biomed. Eng. 2008, 36, 661-671.

(162) Mukthavaram, R.; Shi, G.; Kesari, S.; Simberg, D. Targeting and depletion of circulating leukocytes and cancer cells by lipophilic antibody-modified erythrocytes. J. Controlled Release 2014, 183, 146153.

(163) Wang, C.; Sun, X.; Cheng, L.; Yin, S.; Yang, G.; Li, Y.; Liu, Z. Multifunctional Theranostic Red Blood Cells For Magnetic-FieldEnhanced in vivo Combination Therapy of Cancer. Adv. Mater. 2014, 26, 4794.

(164) Soppimath, K. S.; Aminabhavi, T. M.; Kulkarni, A. R.; Rudzinski, W. E. Biodegradable polymeric nanoparticles as drug delivery devices. J. Controlled Release 2001, 70, 1-20.

(165) Xie, Z.; Zhang, Y.; Liu, L.; Weng, H.; Mason, R. P.; Tang, L.; Nguyen, K. T.; Hsieh, J. T.; Yang, J. Development of Intrinsically Photoluminescent and Photostable Polylactones. Adv. Mater. 2014, 26, 4491-4496.

(166) Schmaljohann, D. Thermo-and $\mathrm{pH}$-responsive polymers in drug delivery. Adv. Drug Delivery Rev. 2006, 58, 1655-1670.

(167) Bajpai, A.; Shukla, S. K.; Bhanu, S.; Kankane, S. Responsive polymers in controlled drug delivery. Prog. Polym. Sci. 2008, 33, 10881118.

(168) He, H.; Ye, J.; Wang, Y.; Liu, Q.; Chung, H. S.; Kwon, Y. M.; Shin, M. C.; Lee, K.; Yang, V. C. Cell-penetrating peptides meditated encapsulation of protein therapeutics into intact red blood cells and its application. J. Controlled Release 2014, 176, 123-132.

(169) Bawa, P.; Pillay, V.; Choonara, Y. E.; Du Toit, L. C. Stimuliresponsive polymers and their applications in drug delivery. Biomed. Mater. 2009, 4, 022001. 